Fakultät III

Wirtschaftswissenschaften, Wirtschaftsinformatik und Wirtschaftsrecht

Volkswirtschaftliche Diskussionsbeiträge

Discussion Papers in Economics

No. 167-14

August 2014

Lars-H. R. Siemers

A General Microsimulation Model for the EU VAT with a specific Application to Germany 
Universität Siegen

Fakultät III

Wirtschaftswissenschaften, Wirtschaftsinformatik und Wirtschaftsrecht

Fachgebiet Volkswirtschaftslehre

Hölderlinstraße 3

D-57068 Siegen

Germany

http://www.uni-siegen.de/fb5/vwl/

ISSN 1869-0211

Available for free from the University of Siegen website at http://www.uni-siegen.de/fb5/vwl/research/diskussionsbeitraege/

Discussion Papers in Economics of the University of Siegen are indexed in RePEc and can be downloaded free of charge from the following website:

http://ideas.repec.org/s/sie/siegen.html 


\title{
A General Microsimulation Model for the EU VAT with a specific Application to Germany
}

\author{
Lars-H. R. Siemers* \\ Department of Economics and FoKoS \\ University of Siegen \\ Hölderlinstraße 3 \\ 57076 Siegen, Germany \\ lars.siemers@uni-siegen.de
}

This version: August 2014

\begin{abstract}
The sales taxes in the EU-and in several other countries - are practiced as valueadded tax of the consumption type with invoice method. Literature on microsimulation models (MSM) for this type of VAT is rare, though the importance of VAT has continuously increased. We discuss the issues of VAT-MSM in detail and develop a basic general VAT-MSM, applicable to the EU member states (and beyond). To illustrate the functioning of the general model, we apply it in detail to the specific case of Germany. We provide comprehensive estimation results for the distributional and fiscal effects of the German VAT. Finally, we simulate the effects of a small VAT reform in 2010, comparing static and behavioral response simulations.
\end{abstract}

Keywords: VAT microsimulation · VAT exemption $\cdot$ RWI-VAT-SIM $\cdot$ EU

JEL: $\quad \mathrm{H} 22-\mathrm{H} 24 \cdot \mathrm{C} 6 \cdot \mathrm{D} 12 \cdot \mathrm{D} 31 \cdot \mathrm{D} 63$

${ }^{*}$ I am highly in debt to Bernd Fritzsche, who started the development of the simulation model for Germany at RWI Essen, documented in Fritzsche et al. (2003). After a common project I had the honor to succeed him after his retirement. Over the years, I also benefited from discussions with Heinz Gebhardt, Rainer Kambeck, and Tanja Kasten at RWI. I am also in debt to two anonymous referees for very helpful comments and suggestions for improving the text of this article. Financial support by FoKoS (Research Centre Siegen) is gratefully acknowledged. 


\section{Introduction}

Value-added taxation (VAT) is currently one of the major pillars of generating tax revenue to the governments. In many countries of the European Union (EU) VAT rates have increased and reforms are discussed. Fairly surprising, therefore, is a lack of comprehensive (micro-)simulation literature in this field. The article tries to fill the gap by a comprehensive discussion of VAT issues in the context of microsimulation. We provide a model for the most widespread form of VAT, the VAT of the consumption type with invoice, that is applied in the EU. The model ought to function as a blueprint for any microsimulation model (MSM) for this kind of VAT.

\subsection{Theoretical Background and Historical Retrospection}

There is an old theoretical debate about how to mix direct and indirect taxes. In the preWWII era the use of indirect taxes was rejected because of its excess burdens (Marshall 1920; Hicks 1939; Joseph 1939). After the war, in contrast, Wald (1945) and Henderson (1948) argued that direct taxes generate excess burdens alike when labor supply is flexible: the disincentive to work induced by direct taxation of income could be much more severe than that of indirect taxation. Corlett and Hague (1953) showed that, under certain conditions, a revenue-neutral change from income taxation toward an ad-valorem commodity tax can increase real income. Following their famous leisure-complementarity rule the optimal tax rate increases with the degree of complementarity to the nontaxable leisure. Indeed, the modern empirical literature suggests that the labor-leisure distortion is the most important feature of inefficiency (Meghir and Phillips 2010). The labor supply decision is distorted by both tax types, however, either via the net nominal wage or via the consumer prices in the denominator. ${ }^{1}$ Given societies do not only have efficiency concerns but also distributional aims that determine welfare, later literature combines the issue of distortions (efficiency) and social distributional preferences. The production efficiency theorem states, however, that aggregate production efficiency is a precondition of optimal taxation (Diamond and Mirrless 1971). There are two strands of approaches, founded by Ramsey (1927) and Mirrlees (1971), that demonstrate that the optimal mix of direct and indirect taxation depends on a complex set of determinants (e.g., Atkinson and Stiglitz 1976). While from a theoretical point of view there might remain some justification for

\footnotetext{
${ }^{1}$ Remind that the labor supply is determined by the net real wage.
} 
differentiating tax rates on different goods, the decisive reasoning for unified rates roots in administrative efficiency (e.g., Harberger 2002; Crawford et al. 2010; Ismer et al. 2010): (i) different rates generate incentives for tax evasion strategies; (ii) differentiated rates cannot be effectively used for distributional aims, as all non-targeted households that consume the reduced-taxed goods benefit huge inefficient windfall gains. Direct taxes might appear as the more efficient instruments for distributional aims, therefore. ${ }^{2}$

In practice, VAT turned out to be the most important form of indirect taxation - and VAT reform got a never ending policy debate worldwide. A history of the VAT is provided, e.g., in James (2011). The probably first documented demand for a modern VAT was provided by Wilhelm von Siemens at the beginning of the German Weimar Republic in 1919 (Ito 1954). ${ }^{3}$ After WWII there was a trend toward the introduction of VAT and toward an increasing degree of reliance to it (Harberger 2002: 3). The EU introduced the VAT already in the 1960s. ${ }^{4}$ The VAT substituted the so far used turnover taxes that represented gross VAT (or production type VAT). In contrast to the modern net VAT (or consumption type VAT), the VAT burden ${ }^{5}$ on the typically taxed inputs accumulates over the production chain in the gross VAT case, because the VAT burden on intermediary goods is not deductible. This problem of accumulating VAT burdens over the production chain hence increases prizes ("cascade effect") and thus generates an incentive to concentrate, in order to be more competitive. Similar reforms toward net VAT arose in Latin America in the 1970s and in other developed economies such as Australia, Canada, Japan, and Switzerland in the 1980s. Many transitional and developing countries in Asia and Africa followed afterward (James 2011). An important recent instance is China, that launched a VAT reform in 2009, where in mainland China the gross VAT was substituted by a net VAT (Lu and Chen 2008). For Cnossen (1998) the widespread introduction of VAT was the most important tax reform aspect in the second half of the last century.

\footnotetext{
${ }^{2}$ The literature does not address external effects. These ought to be addressed by special Pigou taxes, but not in the framework of VAT.

${ }^{3}$ In the U.S., often also Thomas Adams is named (James 2011).

${ }^{4}$ Following the advice of the EC Fiscal and Financial Committee in 1962, all EC member states introduced a net VAT with a pre-tax allowance right from the early years of the EC, starting in 1965/1958. A first limited form was introduced in France already in 1954, in the pre-EC era. Italy, the final original EC member state that performed the change over, introduced it in 1973. All later members had to introduce a VAT, too, for instance, Ireland (1972), the UK (1973), or Spain (1986) (Jenkins and Lamech 1991). Denmark established a full national VAT in 1967 (James 2011), before membership.

${ }^{5}$ To prevent confusion, a remark on our diction is apposite. We refer to 'VAT burden' or 'burden' in this article to address the VAT that is actually borne via consumption expenditures. These have to be distinguished from any excess burdens that may arise, too. Excess burdens due to deviation from Pareto optimum are additional efficiency cost we do not cover. Whenever we mean excess burden we explicitly label it as such.
} 
The very most members of the EU do not use unified rates. Economists hence suggest unified rates by abolishing reduced rates, tax free expenditures, and exemptions (e.g., Boeters et al. 2010; German Council of Economic Experts 2010; Peffekoven 2010). Moreover, a harmonization of VAT rates, especially the EU rules for reduced VAT rates, has been discussed since long ago (cf. Copenhagen Economics 2007), since this would, at least theoretically, establish a Pareto efficient international goods taxation within the EU (Haufler 2001). And especially in times of high unemployment rates, ways of reducing labor cost has been intensively discussed, mainly with a focus of reducing the employers' contributions to the social insurance system by a switch to a system of financing it to a higher extent by indirect taxes, especially VAT. Political decisions on such comprehensive VAT reforms, however, require robust, trustworthy estimates of the economic, distributional and fiscal effects of all potential reform options. The main problem with such an evaluation is, however, that all potential reform scenarios cannot be observed, that is, represent counterfactual situations. If similar reforms have been undertaken by other regions, regression and evaluation studies of these reforms will help to evaluate particular reform scenarios, but always only the one realized there - and still the effects in the own region may differ. Therefore, for a well-informed political decision governments ought to collect more detailed region-specific information on all discussed reform scenarios and beyond. The tool for such evaluations are estimates via models that simulate the non-observable counterfactual scenarios.

The described discussion of VAT reform stresses the importance of valid evidence on the effects of indirect taxation. In 2011, 'indirect taxes' (34.5\%), 'direct taxes' (33.2\%) and 'social contributions' (33.5\%) each accounted for about a third of the EU-27 total tax burden. These numbers differ markedly between the members, however: the fraction of indirect taxes varies between $30 \%$ in Belgium and Germany to $54 \%$ in Bulgaria (Eurostat 2013: 27). Typically, in developing and emerging economies, indirect taxes are even more important. For instance, in China the fraction of indirect taxes is about $75 \%$ (Nie and Yue 2012).

\subsection{Relation to the Simulation Literature}

Simulation models based on macro data are often sufficient for fiscal and macro effects. The official VAT estimates of the German Federal Ministry of Finance (and probably of many other countries) root in an internal, non-public macro-simulation model, mainly 
at basis of the national account data on household expenditures; a seminal paper in this context is Boss (1997). These simulations are used, for instance, in the context of the biannual tax estimations for the budget planning or the estimations in the context of reform plans for the ministry. Bosch and van den Noord (1990) demonstrate how important the details of a switch in financing the social system are for the resulting macroeconomic effects. For the Netherlands at the beginning 1990s they compared the alternatives of a budget-neutral substitution of social contributions by an (i) extension of the current levy such that the levy base is not anymore only wages but all income, (ii) increase of VAT rates, and (iii) integration of the levy of premiums in the income tax. The alternatives partly have strikingly different macroeconomic effects. The authors do not prefer increased VAT rates but alternative (i), because it bears the strongest positive employment effect. The results of the EU simulation model QUEST on the proposal of a revenue-neutral rebalance of financing toward indirect taxation suggest that this strategy might be weakly effective for pushing growth and employment in some EU countries, but that it is definitely no panacea (European Commission 2006). ${ }^{6}$ Bye et al. (2012), in turn, simulate in a computable general equilibrium model VAT reforms in Norway and demonstrate that an incomplete shift to a uniform VAT may be even Pareto-inferior, while the complete shift is Pareto-improving. These macrosimulation models are all behavioral models, that is, they incorporate potential behavioral responses of the economic agents. Crawford et al. (2010) argue that the optimal mix of direct and indirect taxes is, however, rather a matter of administrative efficiency and compliance cost.

In the political debate on VAT it is the distributional (and other socioeconomic) effects that are in the center of the debate. Based on macro data alone, the incidence effects remain open. Input-output models - developed, e.g., by Scutella (1999) and reviewed by Warren (2008) - allow to disaggregate macro data to the many industry sectors and the few final consumption types that are documented by the national input-output tables. This method allows, for instance, Nie and Yue (2012) to distinguish rural and urban areas, as well as poor and rich individuals in China, in order to draw inequality conclusions of the effects of indirect taxation. ${ }^{7}$ Generally, only micro data, that is, representative data on at least all relevant groups of society and its specific expenditures, allow to deduce the distributional and socioeconomic effects, however. While Nie and Yue (2012) are able to identify final consumption in the areas of exports, imports, rural and urban household final consumption, respectively, as well as government final consumption, cross fixed capital

\footnotetext{
${ }^{6}$ A pessimistic opinion is, e.g., given in Jackman et al. (1996).

${ }^{7}$ Cf., e.g., Nie and Yue (2012) for a recent survey of input-output model analyses.
} 
formation, and changes in inventories, adequate micro data allow to identify in detail expenditures for a bundle of different specific goods of single households with manifold different mixes of characteristics (see below). Therefore, micro data - if available - allow in depth analyses beyond input-output approaches.

As Decoster et al. (2011: 41) emphasized "the prominent role of the consumption tax instrument both in practice ... and in the public debate, stands in sharp contrast with the poor attention it got within the microsimulation community." Especially, the literature on the incidence of indirect taxation in Europe is quite small. Most work on microsimulation has been done in the area of direct taxes (Decoster et al. 2011). ${ }^{8}$ MSMs on indirect taxes are rare. Besides our model, the German VAT is also simulated in Bach (2005) and Ismer et al. (2010), who both are geared to our basic model in Fritzsche et al. (2003). These MSMs are static and do not incorporate behavioral responses. Boeters et al. (2010) simulate the German VAT in an applied general equilibrium (AGE) model and deduce a welfare as well as a distribution analysis for some revenue-neutral reform options. The study uses German micro data, but aggregates the data to only three groups (terciles of income) that are incorporated in their AGE model. That is, it improves the analysis of behavioral responses but is weaker with respect to in depth incidence analysis and represents only a semi-micro data model. A less recent welfare analysis of VAT is Kaiser and Spahn (1989), who also use micro data where 13 commodity expenditures were distinguished. The study is normative, however, and tries to deduce empirically the optimal structure of VAT rates in West Germany. There are also two papers addressing redistributive effects of indirect taxes (including VAT) applying EUROMOD, where different EU member states are studied (O'Donoghue et al. 2004; Decoster et al. 2011). ${ }^{9}$ Both extend EUROMOD by an indirect-taxes module and propose to overcome the lack of expenditure data, required to simulate indirect taxation, by imputation techniques. What is missing, however, is a rigorous documentation of the VAT issues to be accounted for by MSMs. Following Decoster et al. (2011) most MSMs “... have focused on the arithmetic micromodeling of personal income taxes, social security contributions and benefits" instead of addressing indirect taxes, because they attribute a "relative simplicity" to most VAT and

\footnotetext{
${ }^{8}$ Existing income tax-benefit MSMs are provided, e.g., by Ericson and Flood (2012), or Peichl and Schaefer (2009). Surveys can be found in Wagenhals (2004) and Zwick and Merz (2007). Additionally, there exists the tax-benefit model for the European Union EUROMOD.

${ }^{9}$ The first paper covers Belgium, Finland, France, Greece, Ireland, Italy, Luxembourg, the Netherlands, Portugal, Spain, Sweden, and the United Kingdom, the second Belgium, Hungary, Ireland, and the U.K. In both studies Germany is not included. Note that the German data for EUROMOD, the German SocioEconomic Panel (GSOEP), do not provide the required expenditure data for a VAT microsimulation.
} 
excise systems. As will become clear, the EU VAT system is in detail-especially due to "hidden" elements - also complicated, and a founded simulation requires a bundle of expert knowledge. An important issue are the strict data requirements, however.

This article discusses in detail all VAT issues to be accounted for and provides a general MSM for the VAT type applied in the EU, and beyond. In particular, we emphasize that there a more than the obvious open VAT burdens, we all are aware of. Due to several exemptions stated in the VAT laws there are further hidden VAT burdens (Gottfried and Wiegard 1991) that are borne by the individuals - and very often neglected in VAT analyses. Our VAT simulation model covers all differentiated VAT rates and exemption effects. Though we do not use a general equilibrium model, we allow for behavioral responses due to price elasticities of demand, so that our model is a semi-behavioral model. In a second step, a specific application to the German VAT is performed and explained in detail, to illustrate the functioning of the model in practice. The German case is an instance where the model does not suffer from a lack of sufficient micro data on expenditures. This application also serves as a documentation of the VAT simulation model that we developed at RWI Essen for Germany, which, hereafter, we will label 'RWI-VAT-SIM'. We extend the static RWI-VAT-SIM to a semi-behavioral model, however, and incorporate some further improvements. Overall, this article basically performs three contributions: (i) a general survey on the background of VAT and the issues to be accounted for; (ii) providing a comprehensive general MSM for the EU type of VAT; and (iii) a detailed application of it to Germany as a demonstration of the functioning and the abilities in detail. The article ought to provide the theoretical basis for the development of VAT MSMs for the EU member states (and beyond). A specific application of our general EU VAT model to other EU members, however, is contingent on the availability of the required data at sufficient quality. Hence, we also address this issue in more depth below.

The article is structured as follows. In section 2, we explain the general VAT type practiced in the EU, and in section 3, we present the EU VAT regulation, in order to develop a general VAT MSM for the EU, which is performed in section 4. The application to Germany follows in section 5. In Section 6, we provide some specific simulations to demonstrate the possibilities of the MSM. Finally, we conclude by summarizing the major lessons for researchers who wish to replicate the model and briefly discuss potential future research issues in section 7 . 


\section{The VAT of the Consumption Type with Invoice}

The intention of VAT is that the final burden of VAT is borne by the consumer. The special element of the net VAT is the invoice or credit method of accounting, that, de facto, guarantees that consumption is the tax base (Jenkins and Lamech 1991). In this system the purchase tax is a tax that only burdens the net value added of a good or service, measured over all steps of the production chain. That is, it is a net value-added tax at each state of production with the right of input-tax deduction, which, at least in theory, prevents the well-known cascade effects of sales taxes of the gross VAT type. In order to achieve that only the net value added is taxed, the invoice method put on order that sellers of products have a claim to subtract all VAT payments having paid on inputs and investment goods from the amount of VAT revenue it earned at selling its final goods, that is, the effective revenue to be transferred to the fiscal administration is statutory VAT on turnover minus VAT paid on inputs and investments of the firm. Therefore, no pre-burden is accumulated over the production chain and the final consumer only pays the official VAT rate applied to net value added. The VAT typically is an ad valorem tax: the seller of a good adds the VAT rate, labeled $\tau$, to the producer or net prize, labeled $p$. It is the consumer that should bear the tax burden via the consumer or gross prize $p \cdot(1+\tau)$. So the VAT is a form of consumption tax where the seller is considered to only channel the tax revenue to the state. In practice, as is well known in public economics, this tax shifting is limited in the short-term due to market conditions such as the degree of competition and the size of the price elasticity of good demand relative to supply (Musgrave and Musgrave 1984: 453-457).

The VAT of the consumption type with invoice have to be applied in all EU member states. From an international perspective of trade, the VAT of the consumption type allows the implementation of the destination principle, which is the principle the international community has agreed on in the context of the GATT rules (Haufler 2001: p. 148). The destination principle requires that internationally traded goods are taxed in the country where it is consumed. ${ }^{10}$ Further advantages are discussed, for instance, in Musgrave and Musgrave (1984) or Jenkins and Lamech (1991). Right from the beginning of the European integration after WW-II indirect tax harmonization was focused (Haufler 2001: p. 22). In the Tinbergen Report (1953) it was argued that taxation in the country of consumption (destination principle) or in the country of production (origin principle) is

\footnotetext{
${ }^{10}$ The alternative is the origin principle where the goods are taxed where they have been produced, irrespective of where they are consumed (Haufler 2001: p. 148).
} 
basically equivalent as long as a harmonized single tax rate is applied. In the Neumark Report (1963) the authors suggested substituting the gross VAT forms, used these days, by the net VAT, which has been followed in 1967. They recommended the origin principle, whereas the EU VAT is geared to the destination principle. ${ }^{11}$ Recent literature shows that the welfare effect of tax harmonization, however, is indeterminate, irrespective of the tax principle. That is, harmonization can, in fact, be harmful (e.g., Kotsogiannis and Lopez-Garcia 2007). ${ }^{12}$

\section{The Basic Structure of the EU VAT System}

VAT Directive 2006/112/EC only provides a general harmonized common legal framework. It directly distinguishes explicitly between a standard rate and reduced rates (pp. 23-26) and handles a huge number of allowed exceptions (European Union 2006: 27-35). Consequently, the EU member states continue to distinguish between different forms of consumption in the respective national VAT laws. There is a general standard rate on all purchases stated, but the respective laws explicitly state long lists of goods and services that are taxed at, sometimes up to three, reduced rates. The typical candidate for the reduced rate in most EU member states are the expenditures for food, but there are many other expenditures like those for books, newspapers, journals, cultural events, or local public transport that are enjoying reduced VAT rates in many member states. Moreover, there are a number of consumption transactions that are, de facto, taxed at a rate of zero. The major tax exemptions (tax rate of zero) involve all sales that represent exports, in order to establish the destination principle of international goods taxation and guaranteeing the consistence with the EU tax treaties. But there are further instances in many countries, like expenditures for rents (for dwellings, resp. housing), or sales in the context of sea shipping and aviation. And the goods with a rate of zero have to be distinguished further, depending on the specific details referring the invoice method, as we explain below.

In this EU VAT system with these general three tax rates (standard, reduced, zero), each

\footnotetext{
${ }^{11}$ Given the internal common market of the European Economic Community, the destination principle cannot be administered completely. Hence, some elements exist that follow the origin principle. Consequently, the EU system is labeled 'mixed tax principle' (Haufler 2001: 151). Readers interested in more details of the EU VAT issues and beyond are referred to, e.g., Keen and Smith (1996) and Haufler (2001).

${ }^{12}$ Bye et al. (2012) also state that a uniform general VAT system is not the most efficient system, $a$ priori. An interesting evaluation of the VAT beyond second-best theory is given in Keen (2007).
} 
member state has the right to set deviating national levels of the respective VAT rates. The only tax-rate harmonization rule is that the standard rate $\tau_{c}^{s}$, where index $c$ represents the specific country, has to be at least $15 \%$ and that at most two reduced rates of not less than 5\% may be applied to goods and services enumerated in restricted lists. The EU Directive on the common system of VAT and single accession treaties, furthermore, allow manifold special national deviations from these basic rules, which complicates the EU system further. As a result, there exist also a "super reduced rate" and/or "parking rate" in nine member states on particular goods and/or services, where parking rates are special intermediate rates. ${ }^{13}$ The complete set of applied rates in the EU is summarized by Table 1. As can be seen, for instance in Luxembourg and Ireland, there are partially five different VAT rates valid at the same time. Hence, we have to introduce six VAT rates for an EU MSM: standard rate $\tau_{c}^{s}$, the first reduced rate $\tau_{c}^{r 1}$, the second reduced rate $\tau_{c}^{r 2}$, a super-reduced rate $\tau_{c}^{s r}$, a parking rate $\tau_{c}^{p}$, and a rate of zero, with $c=1, \cdots, 28$ representing the current 28 member states of the EU. Only Denmark applies one single VAT rate to all goods and services that are not exempted. Even the standard rate ranges between 15\% (Malta) and 27\% (Hungary).

An important issue, that makes VAT systems significantly more complex, are the legal rules of the credit method ${ }^{14}$ referring specific purchases of goods de facto taxed at a rate of zero. The credit method would be simple if all entrepreneurs and companies would have a claim on the credit on the VAT burden at their inputs in the production chain. While some final sales are not taxed and, at the same time, the entrepreneur still has a claim on tax credits for input burdens (zero-rating), others are not taxed, too, but the entrepreneur has no tax credit claim for VAT burdens on his inputs or investment goods (VAT exemption), with the consequence that there remains the VAT burden on all inputs. So there are distinct differences between these two cases, though, at first sight, both sales are burdened at a VAT rate of zero (Jenkins and Lamech 1991; Gottfried and Wiegard 1991). In the case of zero-rating, the final product is sold without (national)

\footnotetext{
${ }^{13}$ For instance, in the course of the negotiation of the accession treaty Austria was guaranteed the right for a special VAT rate for their winegrowers. While the reduced rate in Austria is $10 \%$ and the standard rate is $20 \%$, wine is taxed at parking rate $12 \%$.

${ }^{14}$ Here, a hint is apposite to prevent confusion. In the context of international taxation of income there are different methods to handle the double taxation issue: e.g., exemption method, credit method, deduction method, which all produce different overall income tax burdens (e.g., Luedeke and Voelker 2005: 4,013-4,015). The OECD Model of Double Taxation Convention, however, only allows the use of the exemption or credit method. In the context of VAT, these income-tax-base issues do not arise, however, and 'credit method' simply means that all VAT paid on inputs can be subtracted from the VAT liability on final turnover, as it is the case in the income tax context.
} 
VAT burden. In the case of exemption, in stark contrast, there is at most a partial relief. There is even an extra VAT burden when the sum of input VAT payments exceed the hypothetical tax liability of the final consumption, given by $\tau \cdot p$ : the cascade effect at the production chain remains because there is no claim on subtracting former VAT payments paid for inputs. Note that only zero-rating fully realizes the destination principle, since items with inputs that involve exemptions may still bear national VAT burdens (Gottfried and Wiegard 1991). That is, if national exports bear higher implicit VAT burdens than their foreign counterparts, this represents a disadvantage of international competitiveness. And higher relative implicit VAT burdens due to exemptions also function as import subsidy. Traditionally, the meaning of zero-rating is high in Ireland and the UK, while in France, Germany, and many other EU member states the exemption is used more heavily (Gottfried and Wiegard 1991). Typically VAT systems in the EU (and beyond) make use of both tools simultaneously, however. The quantitative meaning of such distortions is high. Gottfried and Wiegard (1991) estimate that, for instance, in Germany only $63 \%$ of the effective VAT burden is explicitly borne by consumption, and that the residual VAT is intransparently borne by firms via input and investment goods. Firms that have no claim to credit former VAT burdens on inputs and investments, however, will, at least in the long run, shift this VAT burden via consumer prices to the consumers. Therefore, about $40 \%$ of the VAT burden is borne by individuals via intransparent "hidden" channels. To cover all VAT payments, and thus the effective VAT burden of the consumers in an incidence analysis, these implicit hidden VAT burdens due to exemptions have to be taken into account. And the same holds for any estimates for the VAT revenue of the state or budgetary effects of VAT reform options. Neglecting the hidden VAT burdens we will sharply underestimate the VAT burden borne by households and, given an asymmetric distribution of the hidden VAT across different social groups, this will distort the results of any incidence analysis.

\section{A General Microsimulation Model for the EU VAT}

For a correct scientific analysis and a powerful evidence-based political consulting a MSM has to address all this complexity as far as possible in estimating distributional and fiscal effects of different possible VAT systems in reform debates. Given up to six different parallel VAT rates we at least require data that allow to distinguish these up to six different expenditures involved as close as possible. If a reform does change the classification of 
the single expenditure groups, we need data that allow to simulate this change, that is, in-depth expenditure information is required: if, e.g., food is not anymore taxed at the super-reduced but at the normal reduced rate we need exact expenditure data on food. This may still be performed by well macro data. If we want to analyze the heterogeneous VAT burden levied on the many relevant social groups, and its changes due to specific reform steps (redistribution), however, the data requirement is much higher, because it demands in-depth information on expenditures and on all individual characteristics to encompass all these groups. This is only possible with highly disaggregated micro data. To draw trustworthy results, we also need micro data that covers this information in a representative sample of individuals or households. The VAT payment is typically not reported in micro data, but only the consumption expenditures. Hence, VAT payments have to be simulated by combining VAT system information with information in the micro data. Especially to simulate the hidden VAT burden, we additionally require national account and input-output statistics that have to be combined with specific in-depth micro data information. The problem with the required input-output tables is that they are documented with significant delay. In the following, we explain how all the discussed VAT issues can be incorporated in a MSM. As will become clear, many further issues got to be solved in detail, and simulating budgetary effects in the framework of MSM requires additional extensions, compared to incidence analysis. A successful application of our model for a EU member state (or elsewhere), however, is always contingent on the availability of the required data for the country considered. ${ }^{15}$

\subsection{Simulation of the VAT Burden}

\subsubsection{The Open VAT Burden}

In a first step, each expenditure or expenditure group in the micro data must be classified according to whether it is liable for VAT. If it is, the correct out of the up to six different VAT rates in the tax law has to be assigned. For this purpose we identify all goods among the liable that qualify for each single reduced or special VAT rate, according to the comprehensive respective lists in the VAT law. The residual goods and services that are liable for VAT are all taxed at the standard rate. Let us address 'goods and

\footnotetext{
${ }^{15} \mathrm{~A}$ survey of adequate microdata in all $\mathrm{EU}$ members is beyond the scope of this article. In the end, only a successful application of the model using a particular micro-data set will prove that the data requirement is fulfilled, respectively. In the U.K., for instance, we expect that the UK Integrated Household Survey is providing sufficient expenditure information for a successful application. For Germany, see below.
} 
services' simply by 'goods' in the following, for simplicity. Let $\mathcal{S}_{c}$ denote the set of goods $i, i=\{1, \ldots, I\}$, that are taxed at standard rate $\tau_{c}^{s}$ in country $c, \mathcal{R}_{c}^{1}$ the set of goods $i$ that are taxed at the first reduced rate $\tau_{c}^{r 1}, \mathcal{R}_{c}^{2}$ the set of goods $i$ that are taxed at the second reduced rate $\tau_{c}^{r 2}, \mathcal{S} \mathcal{R}_{c}$ the set of goods $i$ that are taxed at the super-reduced rate $\tau_{c}^{s r}, \mathcal{P}_{c}$ the set of goods $i$ that are taxed at the parking rate $\tau_{c}^{p}$, and $\mathcal{Z}$ the set of goods $i$ taxed at a rate of zero. We obtain $\mathcal{S}_{c}+\mathcal{R}_{c}^{1}+\mathcal{R}_{c}^{2}+\mathcal{S} \mathcal{R}_{c}+\mathcal{P}_{c}+\mathcal{Z}_{c}$ being equal to the set of all $I$ consumption goods that are liable for VAT in country $c$. Given we consider only one country we drop subscript $c$ in the following, for simplicity, and obtain:

$$
\tau_{i}=\left\{\begin{array}{lll}
\tau^{s} & \text { if } & i \in \mathcal{S} \\
\tau^{r 1} & \text { if } & i \in \mathcal{R}_{1} \\
\tau^{r 2} & \text { if } & i \in \mathcal{R}_{2} \\
\tau^{s r} & \text { if } & i \in \mathcal{S} \mathcal{R} \\
\tau^{p} & \text { if } & i \in \mathcal{P} \\
0 & \text { if } & i \in \mathcal{Z}
\end{array}\right.
$$

for any $i \in[1, I]$, and with $\tau^{s} \geq \tau^{p} \geq \tau^{r 1} \geq \tau^{r 2} \geq \tau^{s r}>0$. If in the considered country a particular VAT rate is not used, the corresponding set is empty. The VAT burden caused by these expenditures is fully transparent and noted at the bill. Hence, we call it the open VAT burden, in contrast to the hidden burden. Having allocated to each expenditure the correct tax rate, we obtain the open VAT payments involved by applying the respective implicit VAT rate. Let the expenditures for good $i$ of individual $j$ be denoted by $E_{i j}$. We know that the consumer price is given by $p_{i} \cdot\left(1+\tau_{i}\right)$, where $p_{i}$ is the producer price ${ }^{16}$ of good $i$. Hence the net (or before-VAT) expenditures are obtained as $\frac{E_{i j}}{1+\tau_{i}}$, which represents the tax base of the VAT. Therefore, the corresponding VAT burden on expenditure $i$ is simulated as $\tau_{i} \cdot \frac{E_{i j}}{1+\tau_{i}}$, with $\tau_{i} /\left(1+\tau_{i}\right)$ being the implicit VAT rate on expenditure $i$. It

\footnotetext{
${ }^{16}$ If there are further excise taxes there would be a further wedge between the net-of-VAT consumer price and the producer price. Typically, the VAT is applied as the final commodity tax, so that the approach continues to be valid.
} 
follows that the total open VAT burden of micro unit $j$, denoted $V A T_{j}^{\text {open }}$, is given by: ${ }^{17}$

$$
V A T_{j}^{\mathrm{open}}=\sum_{i=1}^{I} \tau_{i} \cdot \frac{E_{i j}}{1+\tau_{i}}
$$

A mistake sometimes done is to calculate the VAT burden as $\tau_{i} \cdot E_{i j}$, that is, applying the explicit instead of the implicit VAT rate. This highly overestimates the VAT burden. ${ }^{18}$ Note that we assume a complete shifting of the VAT toward consumers. This assumption is in line with Crawford et al. (2010) and has also been raised for the Australian indirect taxation (Scutella 1997: 36). The empirical evidence on the degree of VAT shifting by the producers, however, is still not fully developed. As theory suggests, goods with different market structure (competition etc.) have different levels of incidence: for some goods under-shifting is found, for others full or even over-shifting, so that a full shifting is arguable (e.g., Besley and Rosen 1999; Carbonnier 2007; German Council of Economic Experts 2007). Poterba (1996) and Deutsche Bundesbank (2008), using very good indetail data, support the assumption of a complete shifting for the U.S. and Germany.

\subsubsection{The Hidden VAT Burden}

As discussed above, the open VAT burden is by far not the actual VAT burden borne by consumers, because, though not transparent on a bill, individuals also bear VAT burdens on several further goods beyond that open burden via VAT shifting. When firms sell goods that are exempted from VAT, the production of this good required the input of commodities that were burdened by VAT, nonetheless. In the case where the tax law does not allow any claim on a credit for this VAT burden borne at former stages of the production chain (VAT exemption instead of zero-rating), the firm would, ceteris paribus, face a VAT burden, although the intention of VAT is that the final burden is borne by the consumer. Hence, firms will most likely shift this VAT burden via the prices to this addressee. That is, the "spurious" VAT exemptions of firms may cause additional hidden VAT burdens. Again, it is true that depending on market conditions this shifting is

\footnotetext{
${ }^{17}$ There might be some expenditure items in the micro data that comprise goods that belong to different VAT rates. In this case, additional statistics must be found to deduce adequate allocation weights, if available. Let $\omega_{i}^{x}, x=\{s, r 1, r 2, s r, p r, 0\}$, be the fraction of expenditures $E_{i j}$ that is spent on goods taxed by $\tau^{x}$. Then, the correct VAT rate $\tau_{i}$ is, in fact, a weighted average of the six possible VAT rates, that is, $\tau_{i} \equiv \omega_{i}^{s} \tau^{s}+\omega_{i}^{r 1} \tau^{r 1}+\omega_{i}^{r 2} \tau^{r 2}+\omega_{i}^{s r} \tau^{s r}+\omega_{i}^{p} \tau^{p}+\left(1-\omega_{i}^{s}-\omega_{i}^{r 1}-\omega_{i}^{r 2}-\omega_{i}^{s r}-\omega_{i}^{p}\right) \cdot 0$. In Section 5 , we explain the procedure in detail for instances in the German data.

${ }^{18}$ If the VAT rate is $20 \%$, as in Austria, Bulgaria, Estonia, France, Slovakia, and the U.K., for instance, the implicit rate is only $16 . \overline{6} \%$.
} 
heterogeneous across commodity items and does not occur ad hoc. It is also conceivable that there exist other shifting channels, for instance, wages. ${ }^{19}$ We assume, however, that in the long term all VAT burdens faced by firms are shifted to the consumers via increased prices, as in the open VAT case.

Which good items are affected by this issue and thus cause additional hidden burdens on consumers is explicitly stated in the single national VAT laws. Typical instances are housing construction, medical services and the health system, the social security system (or national insurance), and private insurances. Many expenditures within these sectors involve VAT burdens, but final products are exempted from VAT, so that these are likely shifted to the private households. As an example, investments for residential buildings are burdened by the standard VAT rate but rents are free from any VAT in Germany. Hence, the VAT most likely is shifted by the investors to the tenants via the rent, although no VAT burden is transparent. Hence, it is not the landlord but the tenant who bears the VAT burden. In the health system, all VAT burdens hospitals, doctors and other actors in the system pay are shifted first to the health insurances, that shift them further to the private households via higher contributions to the social health insurance or higher premiums for private health insurances. The same happens with all other VAT burdens in the context of the social security institutions and other private insurances. Therefore, although the goods seem to not involve any VAT burden because of VAT exemptions, the private households in fact bear them via higher expenditures. Accounting for these hidden burdens significantly changes the specific true VAT burden of different socio-economic groups and hence the distributional effects of a VAT system or VAT reform. Micro data allow to allocate these hidden burdens group-specifically.

Simulating the hidden VAT burden requires a three-step approach. In a first step, we turn back to the goods identified as being exempted from VAT or being not liable for VAT. Within these goods we now have to check whether there are inputs or investments along the production chain that are burdened by VAT but the producers have no claim on a credit for these, so that they may shift it toward consumers in the long run. The researcher must identify VAT burdens not covered by the so far identified open VAT and develop theories how these VAT burdens may be shifted to consumers, as in the example of rents in Germany: rents are not directly burdened by VAT (not liable for VAT) but landlords have no right to assert a claim on the paid VAT for their input and investment expenditures.

\footnotetext{
${ }^{19}$ There exists a related literature on tax incidence in the context of corporate income taxes that suggests these alternatives (e.g., Harberger 2008; Arulampalam et al. 2012; Bauer et al. 2012). However, the incidence mechanism of corporate income taxes may be different to that of VAT.
} 
Identification of hidden burdens and their shifting channels requires a good knowledge of the national VAT law and the respective market conditions. Once we have deduced the relevant expenditures that are additionally burdened by VAT via these indirect channels we use macro data from the national accounts to obtain the total national expenditures in the considered good and year, for instance, the investment expenditures for residential buildings. Let subscript $\tilde{l}$ denote the respective expenditures burdened with VAT in this hidden way, where $\tilde{l}=1, \ldots, \widetilde{L}$, that is, $\widetilde{L}$ is the number of relevant expenditure items "transporting" hidden VAT burdens. Moreover, let $\widetilde{E}_{\tilde{l}}$ denote the total expenditure for item $\tilde{l}$, reported in the national statistics, that is, either directly in the national account or in the input-output tables of the economy. Applying, the same way as described above, the relevant VAT rate on these goods, $\tau_{\tilde{l}}$ (e.g., the rate on investment expenditures for residential buildings) we obtain the total VAT burden involved by this element, labeled $T V A T_{\tilde{l}}^{\text {hidden }}$, by: ${ }^{20}$

$$
T V A T_{\tilde{l}}^{\text {hidden }}=\tau_{\tilde{l}} \cdot \frac{\widetilde{E}_{\tilde{l}}}{1+\tau_{\tilde{l}}}
$$

Summing up all these hidden $T V A T_{\tilde{l}}^{\text {hidden }}$ over the $\tilde{l}$ relevant items, the total hidden VAT burden in the economy amounts to:

$$
T V A T^{\mathrm{hidden}}=\sum_{\tilde{l}=1}^{\widetilde{L}} T V A T_{\tilde{l}}^{\mathrm{hidden}}=\sum_{\tilde{l}=1}^{\widetilde{L}} \tau_{\tilde{l}} \cdot \frac{\widetilde{E}_{\tilde{l}}}{1+\tau_{\tilde{l}}}
$$

The crucial question is how to distribute this total macroeconomic hidden VAT burden $T V A T^{\text {hidden }}$ to the micro units, that is, to the private households or individuals. Based on the developed theories, the hidden burden is shifted toward the consumers via specific goods, accordingly denoted by counterpart index $l$. The VAT on residential-buildings investment, for instance, is shifted via the rents. The micro data, in turn, ought to be informative with respect to the expenditures in exactly these items $l$, for instance, rent expenditures. If these expenditures are available the micro data are used to determine each micro unit's fraction of the total expenditures in the considered good, covered in the micro data. The identification strategy for estimating a micro unit's hidden VAT burden is that we apply the fraction of each unit of the respective overall expenditures $E_{l}$ in the micro data, denoted by $f_{l j}$, to the deduced total hidden VAT in this item $l$ based on the macro data, that is, $T V A T_{\tilde{l}}^{\text {hidden }}$. That is, if a household $j$ pays $1 \%$ oo $\left(f_{l j}=0.0001\right)$ of

\footnotetext{
${ }^{20}$ Note that different $\widetilde{E}_{\tilde{l}}$ in the national statistics sometimes might cover similar goods that, however, involve different relevant VAT rates, and hence are to be distinguished via adequate weights.
} 
the total rent expenditures covered in the micro data $(l)$ we distribute $1 \%$ of the total hidden VAT burden on residential-buildings investment ( $T V A T_{\tilde{l}}^{\text {hidden }}$ with $\tilde{l}$ representing these investments) to household $j$.

For this purpose, we determine the respective fractions of households $j$ in the respective hidden VAT burdens on items $\tilde{l}$ in a second step. We first sum up the respective $l$ expenditures (e.g., rent payments) over all micro units to receive the total expenditures for this item in the micro data, denoted $E_{l}$. Assuming that there are $J$ observations on micro units $j$, that is $j=1, \ldots, J$, we obtain:

$$
E_{l}=\sum_{j=1}^{J} E_{l j}
$$

where $E_{l j}$ denotes the expenditures of unit $j$ in item $l$, reported in the micro data. Micro data fraction $f_{l j}$ then is given by:

$$
f_{l j}=\frac{E_{l j}}{E_{l}}
$$

In a third step, the total hidden burdens on items $\tilde{l}$ at the macro level, $T V A T_{\tilde{l}}^{\text {hidden }}$, are distributed to the households in the micro data via weights $f_{l j}$. That is, each unit's hidden VAT burden, labeled $V A T_{j}^{\text {hidden }}$, is estimated by:

$$
V A T_{j}^{\mathrm{hidden}}=\sum_{l=1}^{L} f_{l j} \cdot T V A T_{\tilde{l}}^{\mathrm{hidden}}
$$

where each item $\tilde{l}$ transporting hidden VAT burdens has its counterpart item $l$ that covers this VAT burden shifted to the consumers in the micro data. It follows that the effective VAT burden of each single micro unit is the sum of the open and hidden burden:

$$
V A T_{j}=V A T_{j}^{\mathrm{open}}+V A T_{j}^{\mathrm{hidden}}
$$

Having simulated the effective individual VAT burden at the micro level we are basically able to perform distributional analyses, for the current system. Simulating any potential VAT reform is easily done by applying the VAT rates of the new system and incorporating any changes of the sets $\mathcal{S}, \mathcal{R}^{1}, \mathcal{R}^{2}, \mathcal{S R}, \mathcal{P}$, and $\mathcal{Z}$. So if the reform scenario is indexed by superscript scen we obtain $\tau_{i}^{s c e n}=\tau_{i}+\mathrm{d} \tau_{i}$. In the static version, the respective VAT is simulated as $\tau_{i}^{\text {scen }} \cdot E_{i j} /\left(1+\tau_{i}\right)$, with $i=1, \ldots, I$; for the hidden burden this approach is analog. That is, we assume that net consumption remains constant at $E_{i j} /\left(1+\tau_{i}\right)$ 
and there is no real behavioral response, but the expenditures change according to the changed VAT rate applied to the constant net consumption. Consequently, the budget constraint demands for modifications of the other demand items. We assume a modification of savings alone, for simplicity. In so doing, we only account for the direct effects of reforms. After a tax rate reduction, for instance, there remains a positive fraction of the budget that may increase consumption of other commodities than savings and, thus, VAT revenue. It follows that we may overestimate the budget effect of the VAT relief. A correct distribution of the income effect, however, is only possible by a restrictive assumption on preference functions - and the additional indirect effect is, in comparison, probably merely small. Given that $\mathrm{d} \tau_{i}$ is a change of the consumer price, we would, moreover, expect that consumers will respond according to their price elasticity of consumption. Let the gross price $p_{i} \cdot\left(1+\tau_{i}\right)$ be denoted by $p_{i}^{g}$, and the real consumption (pre-VAT consumption) by $q_{i}$, so that we obtain $E_{i}=p_{i}^{g} \cdot q_{i}$. Assuming $\mathrm{d} p_{i} \equiv 0$, we obtain $\mathrm{d} p_{i}^{g}=p_{i} \cdot \mathrm{d} \tau_{i}$. Given the VAT burden on item $i$ is $\tau_{i} \cdot p_{i} \cdot q_{i}$, its total differential is given by $\mathrm{d} V A T_{i}=p_{i} \cdot q_{i} \cdot \mathrm{d} \tau_{i}+\tau_{i} \cdot p_{i} \cdot \mathrm{d} q_{i}$. With constant income we obtain $\mathrm{d} q_{i}=\frac{\partial q_{i}}{\partial p^{g}} \cdot \mathrm{d} p_{i}^{g}=\frac{\partial q_{i}}{\partial \tau_{i}} \cdot \mathrm{d} \tau_{i}$, so that we simulate the change in the individual VAT payment in the semi-behavioral version as

$$
\mathrm{d} V A T_{i}=\left(1+\eta_{i}^{q}\right) \cdot p_{i} \cdot q_{i} \cdot \mathrm{d} \tau_{i}
$$

where $\eta_{i}^{q} \equiv \frac{\partial q_{i}}{\partial p_{i}^{g}} \cdot \frac{p_{i}^{g}}{q_{i}} \leq 0$ and $p_{i} \cdot q_{i}=E_{i} /\left(1+\tau_{i}\right)$. Chen (1999) as well as Clements and Qiang (2003), for instance, offer cross-country demand elasticity estimates for eight commodity items that can be applied. ${ }^{21}$ If elasticity estimates are not directly available the user can also assume different elasticities and provide results for different scenarios, as a robustness check. Clements (2008: 492) argues that a reasonable first estimate for a price elasticity of a good is $-1 / 2$, whenever no specific estimates are available and broader good items are considered where there are not as many substitutes.

\subsection{Required Extensions for Budget Simulations}

Simulating macro effects, especially the revenue effects, however, requires further steps. If we want to simulate the total VAT revenue our simulation has to cover all VAT payments. It is straight forward to calculate the total private inland-consumption for all items $i$ covered by the micro data, given by $E_{i}=\sum_{j=1}^{J} E_{i j}$ for $i=1, \ldots, I$, respectively. The

\footnotetext{
${ }^{21}$ Chen (1999) provide additionally country-specific estimates, and Clements and Qiang (2003) estimates specific for poor and rich countries.
} 
official national annual private consumption at the macro level is documented in the official national account. Comparing both we are able to deduce the level of coverage of the micro data. As turns out, private inland-consumption in micro data is often underreported (e.g., Fritzsche et al. 2003; Bach 2005; RWI and FiFo 2007). The reason is, next to incomplete declaration in survey data, that micro data often exclude some social groups, due to survey problems. An example is the problem of having to interview groups like homeless persons or people in military barracks and old-age homes. In the context of data privacy and data anonymization, furthermore, the highest-income persons in society are often excluded. Hence, we deduce under-reporting factors by comparison of micro and macro data. ${ }^{22}$

The under-reporting of expenditure $i$ in the micro data is given by $u r_{i}=E_{i} / \widetilde{E}_{i}$, where $\widetilde{E}_{i}$ is the macro number. Then, the correction factor for expenditure $i$, denoted by $c f_{i}^{u r}$, is obtained as:

$$
c f_{i}^{u r}=\left(u r_{i}\right)^{-1}=\frac{\widetilde{E}_{i}}{E_{i}}
$$

That is, if $u r_{i}=0.85$ we use $c f_{i}^{u r}=1.1765$. Conditional on whether there are different consumption patterns among the different groups of the society, this correction can have significant changes in the distribution of the VAT burden. We do not know, however, to which extent the missing consumption is actually undertaken by specific groups. If we increase each consumption item according to the undercoverage factor we will distort the group-specific consumption pattern and thus their specific VAT burden. Consequently, specific reform simulations on distributional effects are biased. For budgetary simulations the distribution of the under-reporting is not decisive, in contrast. Therefore, we do well in separating distributional and budgetary analysis into two simulations for each considered VAT system. Hence, we ought not include these corrections in the incidence analysis.

Applying the correction factors, however, we still neglect the domestic VAT payments of the non-inlanders (foreign tourists or other foreigners who do not live permanently in the country but consume in the considered country) and of the territorial authorities (federal and regional governments as well as the municipalities) and the social security units. Those groups are not covered by micro data or the macro private inlander-consumption data, so that we again have to resort to the national accounts. Total expenditures of the

\footnotetext{
${ }^{22}$ There might be some differences in consumption classification between the national accounts and micro data, which may cause somewhat imprecise estimates in detail. At some higher aggregation level this ought to be no problem, though. At a minimum, we can use the macro level under-reporting factor by comparison of total inland consumption in macro and micro data.
} 
non-residentials is directly reported there. Assigning weights with respect to the correct VAT rate is difficult. Given these people do not live in the country, it is likely that the very most expenditures face the standard rate. Then, the VAT revenue from this source is simply the stated overall expenditures multiplied by $\tau^{s} /\left(1+\tau^{s}\right)$. However, more complicated assumptions can be made.

Simulating the VAT payments of the territorial authorities is more complicated. First of all, the national account contains the gross investment of the territorial authorities, that normally all involve the standard VAT rate. Additionally, these authorities pay VAT on the inputs used to produce the provided goods. The input cost of the territorial authorities can be found in the input-output tables of the official statistics, where again the goods classifications must be ordered by the relevant VAT rate. Again it is plausible to assume that the standard VAT rate is the relevant rate if the good is liable for VAT. Thus, the VAT revenue from these sources can be simulated as for the non-residential.

Finally, in VAT revenue simulations it is imperative to compare the estimated total VAT revenue with that published by the official statistics, to identify estimation errors. It is very unlikely that the microsimulation estimate and the official VAT revenue published coincides exactly. On the one hand, some sources of VAT might be still ignored and cause an underestimation of the revenue, and some items might still be simulated biased. On the other hand, due to the shadow economy and other forms of illegal tax fraud the micro-data estimate might overestimate the VAT revenue. Additionally, in the EU there remains some possibility for VAT arbitrage due to some special rules for small enterprises (Boss 1997: 51-52). The comparison of official published revenue and estimated revenue of the MSM allow to deduce a revenue correction factor, denoted by $c f^{r e v}$ as follows:

$$
c f^{r e v}=\frac{(\text { corrected }) \text { official VAT revenue }}{\text { estimated VAT revenue }}
$$

Depending on the practice of VAT payment, the official published VAT revenue must be corrected for potential lag structures (e.g., Boss 1997). Typically the VAT rooting in taxed expenditures is not directly generating revenue in the same month but with some time lag. If, e.g., the VAT is paid by the firms at a quarterly basis, the published revenue for the year 2014 will actually cover the VAT rooting in the final quarter of the year 2013, and the VAT rooting in the expenditures in the final quarter of 2014 will, in fact, be covered by the published revenue in 2015. Hence, the lag to be corrected for is a quarter, that is, we subtract from the published number the revenue of the first quarter and add 
the revenue in the first quarter of the following year. Even with advance payments, as in Germany, changes due to business cycle and the like are accounted for only with a time lag to be accounted for. The revenue correction factor is especially important in countries where VAT fraud is widespread and the tax deficits thus will be high. In order to correctly quantify the revenue in any VAT reform scenario applying this correction factor is thus imperative. ${ }^{23}$

\subsection{Ordinary Miscellaneous Issues}

There are additional issues that are not VAT specific but relevant in any simulation model. Given the focus here is on VAT MSM, we discuss them only briefly. First, it is important to note that we implicitly assumed that our micro data are representative. Typically micro data will provide us with weights for each observation, that is, an information for how many individuals or households the observation is representative. If the data generation process does not allow to assume that the micro data is an i.i.d. random sample, representativity of the data may not be guaranteed. Micro data typically base on surveys where different groups display different willingness to participate. Therefore, additional statistics have to be used to obtain information on the representative structure of the society. At this basis, representative weights for each single micro unit have to be generated, if not already provided. The reader is referred to the corresponding literature (e.g., Chesher and Nesheim 2006; Fazio et al. 2006).

Another typical issue is data updating or extrapolation. Micro data is often not provided for each consecutive year, but only each three or five years, or even only for one year. If results should be deduced for a specific year the used micro data have to be updated to this year. For years in the past, the relevant macro data are typically at hand up to the last year, unless they have to be taken from input-output tables. The input-output data is only available with many years of delay, so that we can only extrapolate them. For the running year forward projections and estimates have to be used as detailed as possible. If the micro data are generated several years in the past, it is also important to update structural changes in the years that followed, that is, changed fractions of specific social groups, for instance, receivers of unemployment and social benefits. Given

\footnotetext{
${ }^{23}$ It is clear that certain goods may provide more and easier possibilities to tax fraud in practice than others. If consumption patterns among specific social groups differ, a disaggregated correction will improve distributional analyses, therefore. Such a disaggregated approach, however, is infeasible in practice.
} 
distributional analyses typically use total micro VAT burden of a household relative to an income indicator, it is especially imperative to update changes in the income distribution. Again, updating is not a special issue for a VAT MSM and has been discussed in many articles in the literature, for instance, in Deville and Särndal (1992), Gupta and Kapur (2000), Immervoll et al. (2005), and Ball and Creedy (2013). In this context, it is, finally, important to mention that the national account data for about the last four years are experiencing partially significant revisions in the course of time by the statistical offices. Hence, all simulation results based on these data are to be discussed with this qualification, especially when forecasts for the current or even coming year are used.

Given the complexity of the single VAT systems in the EU, the application of the general model to a single member state may involve some specific challenges. As an illustrative example, we demonstrate how the model can be applied to the most populous and, measured by GDP, biggest economy in the EU-Germany.

\section{Application to Germany}

For Germany, this general model has been applied several times in the static version. ${ }^{24,25}$ The German net type of VAT was introduced in 1967/68. There are only three rates: standard rate $\tau^{s}$, reduced rate $\tau^{r}$, and a rate of zero. That is, $\mathcal{R}_{2}=\mathcal{S} \mathcal{R}=\mathcal{P}=\emptyset$ and $\mathcal{R}_{1} \equiv \mathcal{R}$. All transactions taxed at the reduced rate or that are tax-exempted (tax rate of zero) are explicitly stated in the law, respectively (see below). ${ }^{26}$ The standard rate started at 10\% (1968) and is today at 19\% (since 2007). The reduced rate started at 5\%

\footnotetext{
${ }^{24}$ The first version of the model was used for a tax incidence analysis in Fritzsche et al. (2003), and for a project on behalf of the German Council of Economic Experts, where the distributional effects of a VAT-rate increase to finance a planned unemployment-insurance contribution decrease were simulated (German Council of Economic Experts 2005: paragr. 587-591). It was then used to analyze the distributional effects of the German VAT in RWI and FiFo (2007, 2009), and in Beimann et al. (2011). Latest improvements were developed for another research report on behalf of the German Council of Economic Experts, where we extended the model toward estimating budgetary effects of reform scenarios, and, in cooperation with Wolfgang Wiegard, toward distribution-neutral reform alternatives (cf. German Council of Economic Experts 2010: Chapt. 5.II.2, paragr. 386-390).

${ }^{25}$ Some issues discussed here for Germany have also been discussed in the reports mentioned in footnote 24 and in Bach (2005), in German language, however.

${ }^{26}$ Cf. Appendix 2 to $\$ 12$ Abs. 2 No. 1 and 2 in UStG (2011[1967]) for the reduced-taxed goods, and $\S 4$ for the goods taxed at a rate of zero. A detailed discussion and analysis of these transactions can be found in Ismer et al. (2010).
} 
and is today at $7 \%$ (since 1983). We obtain:

$$
\tau_{i}=\left\{\begin{array}{lll}
0.19 & \text { if } & i \in \mathcal{S} \\
0.07 & \text { if } & i \in \mathcal{R} \\
0 & \text { if } & i \in \mathcal{Z}
\end{array}\right.
$$

The only data that can be used for a German VAT MSM is the Income and Expenditure Survey (IES), provided by the Federal Office of Statistics Germany. The survey is representative for many groups covered, and provides information on more than 200 consumption items for more than 40,000 households. The survey micro data is a cross-section provided in a five-years frequency. A detailed description of the data can be found in the Appendix. ${ }^{27}$

RWI-VAT-SIM, so far, was a static and deterministic model, based on the cross-section of micro data provided by the IES. We extend it to a semi-behavioral model by including the price-elasticity responses of demand, and incorporate further improvements. It does not account for further behavioral responses in a general equilibrium setting. Experience shows that incorporating labor supply effects does not change results appreciably. This is backed by the empirical literature: the mean estimate of the labor economists of the leading 40 U.S. universities for the uncompensated labor supply elasticity of men was zero (Fuchs et al. 1998: 1392). In the huge majority of households men are the members with the decisive wage. As stated, we assume that the VAT incidence is fully on consumers, which is considered to be fully valid only in the long run. The data used is the latest wave of the IES, on 2008. In order to focus the VAT specific aspects, results are simulated for the survey year 2008, where all required information is available without any updating or forecasting. ${ }^{28}$

\subsection{The Open VAT Burden}

Based on the German VAT law, the following major expenditures were forming set $\mathcal{R}$ of the reduced taxed goods in 2008: ${ }^{29}$ agricultural and forestry products (including animal feed); food (without luxury food), tea and coffee, milk for humans and particular milk

\footnotetext{
${ }^{27}$ The official data description can be found at the homepage of the German Federal Statistical Office (http://www.destatis.de); search for the text titled "Sample survey of income and expenditure (EVS)."

${ }^{28} \mathrm{~A}$ comprehensive updating procedure for Germany is discussed, for instance, in Merz et al. (2001).

${ }^{29} \mathrm{An}$ exact and complete list is beyond the scope of this article. The interested reader is referred to the German tax law (§12 including its appendix).
} 
products, chocolate drinks, unless served in restaurants and the like, respectively; books and other print products; medical utilities (prostheses, wheelchairs etc.); public transport; works of art; particular leisure events, such as pop and rock concerts, public swimming baths, public zoos etc.; services of non-profit-making corporations. Similarly, the set $\mathcal{Z}$ of the goods taxed at a rate of zero are: exports (including services linked to it); turnover from renting; turnover of charities and the like; particular turnovers of medical service providers and geriatric care; turnovers of money and credit transactions; education; postal services; aviation; public-law broadcasting; cultural events such as theater, opera, orchestra, or museum; turnover that faces a competing special transaction tax, where especially the turnover of private insurances, lottery and gamble are relevant. These goods are exempted from VAT and firms providing them have no claim for a VAT credit, therefore, so that hidden VAT burdens arise. Additionally, the majority of turnover from selling used cars and travel abroad is, de facto, taxed at a rate of zero, just as turnover from prostitution and illegal drugs. We then follow the residual method and determine the set of expenditures burdened with the standard rate, $\mathcal{S}$, as the residual of the documented private consumption expenditures liable for VAT and the set $\mathcal{R}+\mathcal{Z}$.

In detail, some expenditure items in the IES cover elements from different sets, that is, elements that are burdened at different VAT rates. This applies to three major items for the reduced rate: non-alcoholic beverages (variable ef218), public traffic (ef306 and ef307), and events (ef332, ef333, and ef336). Using additional information and statistics we deduce adequate weights, to separate the item to the respective relevant sets $\mathcal{S}, \mathcal{R}$, or $\mathcal{Z}$. Based on Destatis (2012a) and Destatis (2013), we apply a reduced-rate weight of 0.2924 for non-alcoholic beverages, of 0.7 for public transport, and of 0.57 for the events item with respect to $\tau^{r}=0.07$. The rest is taxed at standard rate $\tau^{s}$. Turning to exempted goods and services, there are three major expenditure items that require additional scrutiny: the fraction of exempted rent payments, of used car consumption, and of travel abroad. Due to the fact that the huge majority of used cars is sold by private persons, we assume for used cars a fraction of 0.9 that is involving no tax burden. Following Bach (2005), we assume that a fraction of $10 \%$ of the expenditures for travel abroad represents commissions that are not exempted from VAT. The biggest challenge, however, is the determination of the VAT burden in the context of rents. A major part of the rent payments represents the investment return, and thus does not involve VAT payments for the households. The part of the rent that covers compensation for the standard cost, however, incorporate VAT payments. In the earlier version of the model, 
we estimated the fraction of VAT-burdened rents by a model of financial mathematics (Fritzsche et al. 2003: 184-186). Since RWI and FiFo (2007) we estimate the fraction at basis of exact calculations of the Statistical Office, provided by the micro data: While we do not know the separation between base rent and extra charges in rent payments in the data, the German office calculates for owners imputed base rents separated from imputed condominium fees or common charges. This allows to calculate in the micro data that, on average, the common charges amount to $17.5 \%$ of the complete rent payments. Based on model calculations, e.g., of the German tenant association (DMB 2006), about one-fifth of the extra charges is exempted from VAT, and the residual charges are taxed by standard rate $\tau^{s}$. Therefore, we apply a weight of about 0.86 for the actual rent payments in the category exempted goods. All other expenditure variables are weighted by 1 and do not involve such problems.

\subsection{The Hidden VAT Burden}

In the German VAT system there are four major areas of expenditures where consumers bear VAT burdens in an intransparent way: (i) rent expenditures bear the hidden VAT burden on housing investments; (ii) contributions and premia to health insurances bear the VAT burden on medical services; (iii) contributions to the social security system bear the VAT burden on all expenditures of the social security system; and (iv) insurance premia bear the VAT burden of private insurances.

Ad (i) The expenditures of the investors in housing is taxed at a rate of $\tau^{s}=0.19$ but final consumption of housing via rents is taxed at a rate of zero, so that tenants have no claim on a VAT credit. It is assumed that this VAT burden of the investors is, at least in the long run, completely shifted to the tenants. The complete macroeconomic gross investments in housing in 2008 can be found in Destatis (2012a), ${ }^{30}$ and amounted to nearly $€ 128$ billion (gross equipment investment). Thus, the total hidden VAT burden involved was about $\frac{128}{1.19} \cdot 0.19=20.4$ billion euro. This macro burden is easily distributed to the households via the respective household's fraction of the rent payments in the IES (see above).

\footnotetext{
${ }^{30}$ Note that these national account numbers are regularly changed by the statistical offices due to revisions. These changes can be huge in size. According to experience the revisions change the numbers significantly up to about four years into the future. After this time period, they typically are not changing anymore. The numbers used here, published in a distance of four years, ought to be the valid final numbers, therefore.
} 
Ad (ii) Most investments or input goods of hospitals, doctors, and other actors in the health system are burdened by VAT. These VAT burdens in producing medical services are finally shifted to the health insured via their contributions and premia to the health system. In Germany, we have to distinguish for investments in the fields 'new buildings', that are burdened at the standard rate of 0.19 , and 'new and further equipment', where the reduced rate of 0.07 is levied on. Both macroeconomic aggregates are also documented in Destatis (2012a). Following the same procedure we obtain a hidden VAT burden on these items of about $€ 1.1$ billion and $€ 0.6$ billion, respectively. Additionally, it must be accounted for the VAT burden on used input goods in the health system. These VAT burdened input payments can be deduced from the input-output tables. Since the end of 2012 the 2008 numbers are published (Destatis 2012b); for later years, own interpolations must be used, based on this input-output tables. It is important to note, however, that only those input groups are included that are burdened by VAT, which complicates the task. Once again the list documented in the VAT law is used. Moreover, elements that involve especially wage payments have to be excluded, because they are not burdened with VAT, and the tables including imports have to be used. Doing so, we obtain an additional hidden VAT burden of about $€ 5.3$ billion. In sum, calculated with the precise nonrounded numbers, the health system shifts, in the long run, VAT burdens of about $€ 7.1$ billion to the private households. Calculating the weights $f_{l j}$ in this field is not straight forward. The respective contributions or premia for the health insurance are recorded in the IES for each member of the household. People who are compulsory insured in the statutory health insurance pay the hidden VAT burden via higher contributions. Given in Germany the insured itself pays halve of the contribution and the employer the other halve, the IES is only recording halve of the relevant contribution, so that we double the compulsory contribution recorded in variable ef202. For voluntarily insured in the statutory health insurance (variable ef208), the person pays the complete contribution, so that no doubling is done. Finally, the privately insured pay higher premia as well, so that we account for variable ef211. On average, $40 \%$ of the premium is used to build up reserves for the old age, however. Therefore, we use only the residual $60 \%$ of the premium of privately insured persons in calculating weight $f_{l j}$.

Ad (iii) The social security system also has to pay the VAT for its expenditures over the year. Again we assume that these VAT payments are shifted toward the insured via the contributions to the social security system. It is important to realize that the social security system also covers the statutory health insurance. The hidden VAT burden 
covered by item (ii) only involves the hidden VAT payments that are shifted to the health insurances. We assume that these are shifted forward to the insured. In item (iii) the direct VAT payments of the statutory health insurance are meant, that we neglected so far. Therefore, in the statutory health insurance we do not double count hidden VAT burdens, as it might seem at first sight. Again we have to deal with the gross investments, documented in Destatis (2012a), and the input expenditures, documented in Destatis (2012b). These direct VAT payments are comparatively low. For both expenditures we assume the standard rate to be the relevant and obtain VAT payments of about $€ 0.1$ billion (gross investments) and $€ 0.9$ billion (inputs), which in total amounts to about $€ 1$ billion. The fractions $f_{l j}$ are computed via the complete social security contributions in the micro data, where again the numbers are doubled for non-voluntarily insured.

Ad (iv) Private insurances have no claim on VAT credit, too, and are assumed to shift the VAT via their insurance premium. The investments in new buildings and new equipment of the insurances involve hidden VAT in size of about $€ 0.5$ billion (Destatis 2012a). The input-VAT burden, in turn, amounts to about $€ 4.3$ billion. In sum, this area shifts hidden VAT burden amounting to nearly $€ 5$ billion. For the factor $f_{l j}$ in the insurance sector we use all premium payments of the households documented in the IES.

Overall, the hidden VAT burden that is additionally distributed to the households in Germany amounts to more than $€ 33$ billion.

\subsection{Required Extensions for Budget Simulations}

In order to deduce under-reporting of consumption expenditures in the IES, in a first step, one must deduce the respective total consumption expenditures of the consumption items documented in the micro data (cf. also Fritzsche et al. 2003; Bach 2005). In a second step, the corresponding numbers to these consumption items have to be found in the national account statistic of the Federal Office of Statistics Germany. In Destatis (2012a) the consumption expenditures in current prices is documented distinguished for a very detailed list of usages, that is similar to the IES data item. The comparison and the resulting under-reporting factors for all required expenditure items are documented in Table 2. As an example, in $2008 € 149.14$ billion have been spent for food in Germany. Compared to the total sum of weighted food expenditures documented in the IES, $€ 119.56$ billion, this is 1.25 times more than the micro data report: $c f m c_{\text {food }}=1.25$. Overall, IES2008 covers $81 \%$ of all private consumption expenditures of the residential population, 
which corresponds to an overall correction factor of 1.24 .

Turning to the remaining VAT payments of the non-included economic actors, we again have to ask the national accounts. The consumption expenditures of the non-residential people are explicitly documented in Destatis (2012a): $€ 24.96$ billion. We assume that only $10 \%$ of these expenditures involve the reduced rate $\tau^{r}=0.07$ and the remaining expenditures the standard rate $\tau^{s}=0.19$, which results in an implicit average VAT rate of $15.11 \%$. As for the residentials' expenditures abroad, we assume that $12 \%$ of the expenditures do not involve domestic VAT. Then, the VAT revenue paid by nonresidential people amounts to about $€ 3.8$ billion. The VAT payments of the territorial authorities, in turn, root in VAT payments on gross investments of these authorities and on the inputs used by these authorities. The former is documented in Destatis (2012a) (€38.16 billion), while the latter can be found in Destatis (2012b) (€33.64 billion). We presume the standard VAT rate, respectively. In sum, the VAT payments of the territorial authorities (so without the already accounted for social security system) amounted to about $€ 11.5$ billion. ${ }^{31}$ Table 3 documents the exact estimated building blocks of the VAT micro simulation. The estimated VAT revenue rooting from private consumption amounts to $€ 159.25$ billion. Adding the remaining VAT revenues from non-residentials and state authorities we obtain $€ 174.48$ billion. The actual VAT revenue published by the official statistics for the survey year 2008 amounted to $€ 175.989$ billion (sum of VAT and import sales tax). ${ }^{32}$ Correcting for the phase difference, this revenue is reduced to $€ 175.22$ billion (see Table 3 ). It follows that the required correction factor, rounded to two digits, is cfrev $=1.00$. The simulated revenue is $99.58 \%$ of the true comparable revenue, which corresponds to an estimation error of $-0.42 \%$.

\footnotetext{
${ }^{31}$ These VAT payments do not generate a real net tax revenue of the state as a whole, because these VAT claims at the same time represent VAT responsibilities of the state.

${ }^{32}$ Some remarks are in order on the 'correct' actual VAT revenue. First of all, there are two alternative numbers published on the VAT revenue, one in the classification of the national account (amounting to $€ 172.48$ billion) and one in the classification of the financial statistics, the mentioned $€ 175.99$ billion. For our purpose the financial statistic is the correct one because it measures what VAT payments actually flow in the year, which is consistent with our consumption expenditures recorded in the micro data and with the tax revenue relevant for the government(s). The national account, in contrast, modifies this revenue, among other things, in order to produce a better periodic assignment. Moreover, the used number from the financial statistic includes the so called import sales tax (in German "Einfuhrumsatzsteuer"), which is the VAT on imports. Import tariffs, however, are not included, since they do not represent a VAT. In the calculation of the VAT burden in the micro data we also neglect potential import tariffs, and it is impossible to identify them in the data.
} 


\section{Demonstration of Possibilities}

As documented in Table 3, our simulation reveals that about $72 \%$ of the VAT revenue roots in the open VAT and about $19 \%$ in the hidden part of the VAT burden. $88 \%$ of the open VAT burden originates from the standard rate $\tau^{s}$, while the reduced rate generates only $12 \%$. Within the hidden VAT burden the major item are the housing investments that cause more than $60 \%$ of the hidden VAT. The simulation also allows to deduce the fraction of expenditures that involve the standard, the reduced or the zero rate. $53 \%$ of the expenditures involve 19\% VAT, only $17 \%$ the hotly discussed reduced rate, and $30 \%$ a rate of zero. If we modify this calculation to the actually relevant pre-VAT situation and use as proxy for real, resp. net consumption, the expenditures divided by $1+\tau_{i}$, the fractions of zero rate and reduced rate slightly increase while the fraction of the standard rate decreases to $49 \%$. Compared to the benchmark scenario where the German VAT law would state that all liable expenditures are unified to be taxed at standard rate $\tau^{s}=0.19$, the 2008 system provided VAT reliefs amounting to $€ 86$ billion via open lowerthan-standard VAT rates, which represents nearly $50 \%$ of the total 2008 VAT revenue. The major relief roots in the exemptions (70\%), and not in the reduced rate (only $30 \%$ ). In the following, we present some selected interesting results that ought demonstrate what kind of analyses can be performed by the MSM.

\subsection{Incidence Analysis}

As discussed, the micro data allow to distinguish the VAT burden of many different groups in society. The VAT burden is typically measured by two burden ratios: the VAT payment to household net income (HNI) ratio, or the VAT payment to consumption ratio; for the latter we can again distinguish the VAT-gross-consumption ratio from the VAT-net-consumption ratio. Moreover, this burden indicators can be measured groupspecific as mean or median ratio, that is, the mean of the respective household ratios or the median of the respective household ratios, where the median has the advantage that it is not affected by extreme realizations for single households (outliers) and thus represents the "typical" burden; alternatively, the average burden can also be measured by the ratio of the sum of the VAT payments and the sum of the net household incomes (or consumption) of all group members, which, however, will produce different results compared to the mean, as the first approach represents the mean over all ratios in the group, while the latter represents the average VAT payment per income or consumption 
unit of the group. Regressing the VAT ratios on only a constant by OLS allows to estimate the total mean ratio in the society, and to calculate respective standard errors and confidence intervals, where the standard error can be corrected for any source of heteroskedasticity (robust standard errors) or even for potential cluster effects. To obtain point and interval estimates for the median VAT burden, we use quantile regressions, which allows to estimate any other percentile burden, too. Table 4 presents the results for the median, mean and average burden in 2008. The narrow confidence intervals reveal that the total estimates are not suffering from noteworthy uncertainty.

Repeating the regressions on group-membership dummies allows to deduce any groupspecific burden and to perform t-tests to analyze whether differences are statistical different from each other. Table 5 provides results for major groups on the median net household income, the median VAT payments, the median VAT-burden ratio, and the ratio of median VAT payment and median income. The first two blocks on income deciles and brackets reveal the often discussed regressive character of the VAT, namely that the VAT burden decreases when income rises. In Table 6 we provide the results for the mean burden, including the burden on gross and net consumption. It reveals that the mean burden on HNI is regressive but that the mean burden on consumption is rather progressive, that is, that it rises when income rises. Not surprising, the annual VAT payment is also progressive - though the degree of progressivity is markedly lower than the degree of regressivity on HNI. Table 7 reveals that, indeed, households with low income simply consume more of their net income and thus face a higher VAT burden, compared to households with higher income. Moreover, low-income households consume more heavily the goods that face a reduced or zero rate of VAT, which mitigates the effect of being forced to consume more, as aimed by politicians. The differences are less striking as probably expected, however. A further interesting issue is who finances the VAT revenue of the state. Accumulating the group-specific payments and comparing it to total revenue, we can deduce the sourcing fractions, respectively. Table 8 informs about these fractions for major groups in society. The income-weakest $50 \%$ of the population, for instance, bear only about a third of the VAT revenue, just as the income-strongest 20\%. Having a look on the results for the income brackets, reveals that the persons with a net equivalence income below $€ 40,000$, however, bear nearly $80 \%$ of the VAT revenue. Of course, cross-tables can be produced, too, where one can analyze combinations of the displayed characteristics. The distributional analyses regularly involved additionally inequality and polarization measures, such as the Gini coefficient or percentile ratios etc., which can be 
computed via the micro data, too, to get additional insights in the redistributional effects of the VAT system. Our MSM also allows for the simulation of distribution-neutral reform scenarios and how far potential reform options do deviate from distribution neutrality (cf. German Council of Economic Experts 2010).

\subsection{Reform Simulation}

To illustrate the task of reform simulations, we outline the simulation of the only major change of the German VAT system since 2008. After the EU decided in 2009 that members can apply the reduced rate on some local service goods, the German government reduced the VAT rate on accommodation services of hotels and the like in 2010, too. European Commission (2014) reveals that today 25 out of the 28 member states apply reduced rates on these services. The three missing nations are Denmark, Lithuania, and the U.K. For Germany this meant that hotel accommodation switched from the set of standard rate $\tau^{s}=0.19(\mathcal{S})$ to the goods taxed at reduced rate $\tau^{r}=0.07(\mathcal{R})$. The change in VAT rate thus is $12 \%$-points, $\mathrm{d} \tau_{i}=-0.12$, which represents a reduction by $63.2 \%$. In a static model, the individual VAT payments are simulated as $0.07 \cdot E_{i} / 1.19$, and we assume no real response in consumption. That is, the number of guest-nights remain unchanged. In the semi-behavioral version, we apply a price elasticity of consumption to catch the real response of the individuals, that is, an increase in the number of guest-nights due to lower price.

Hotel-accommodation expenditures $E_{H}$ are covered by variable ef352 in IES2008. The corresponding correction factor is reported in Table 2, too (1.07). The change in VAT on hotel services is then obtained applying Eq. 9, with $\mathrm{d} E_{i}=\left(1+\eta_{i}^{q}\right) \cdot E_{i} \cdot \mathrm{d} \tau_{i} /\left(1+\tau_{i}\right)=$ $\left(1+\eta_{H}^{q}\right) \cdot\left(E_{H} \cdot 1.07\right) \cdot(-0.12) / 1.19$ in the semi-behavioral version. Clements and Qiang (2003: Table 2) do not estimate the price elasticity for hotel accommodation explicitly, but for 'housing' and for 'other'. The estimates for housing is -0.13 for poor and -0.15 for rich countries, respectively for other -0.37 (poor) and -0.32 (rich). We use both elasticities and apply the poor-elasticity to the households belonging to the first five deciles and the rich-elasticity to the second five deciles. In contrast, Boeters et al. (2010: Table 4) report significantly higher total estimates of Chen (1999): specifically for Germany, -0.426 (housing) and -0.547 (other). To localize the effect, we therefore calculate different scenarios for different $\eta_{H}$, documented in Table 9 .

If there is actually an increase of hotel accommodation demand due to lower prices this 
will cause excess demand and thus producer price increases, to reestablish equilibrium. This will decrease demand again. Therefore, the true effect will be located in the range of the static and the semi-behavioral scenarios. There is anecdotal evidence that the gross price for guest-nights did not decrease in the aftermath of the reform. This would imply a scenario where $\mathrm{d} p_{H}^{g}=\left(1+\tau_{H}\right) \cdot \mathrm{d} p_{H}+p_{H} \cdot \mathrm{d} \tau_{H}=0$ (where $\tau_{H}$ and $p_{H}$ represent the initial levels of tax rate and producer price), that is, the price reduction due to reduced VAT rate is fully compensated by an equally high increase due to the producer price. In this scenario, the static model would fit with real world because the absolute and relative prices are unchanged. In contrast to the static model prediction, however, the expenditures would not shrink but remain constant. Former VAT revenue is simply shifted toward producers. ${ }^{33}$

The results above are only briefly presented for the purpose of illustrating the possibilities of the MSM. It is clear that a lot additional discussion of the results ought to be provided in a policy paper, including the interesting discussion of the correct interpretation and of policy implications. Such a comprehensive presentation, however, is not the purpose of this article. Interested readers are referred to the comprehensive research reports on the different issues in German, where many of the issues are analyzed (see footnote 24).

\section{Conclusion}

The importance of VAT for state budgets has continuously increased around the world. Major reforms of VAT are hotly debated. Political decisions on the issue, however, must root in a good understanding how VAT functions and affects especially the budget, the different social groups, and thus the inequality in society. All reform options represent counterfactual situations, that is, situations we cannot observe - and hence must be simulated. While budget and macro effect may be simulated well at basis of macro data, distributional and group-specific effects can only be simulated with micro data.

We discussed a bunch of issues arising when simulating VAT in a MSM. It became clear that, in contrast to a widespread opinion, VAT simulation involves complex processes that must be incorporated in a MSM, too. A major issue in this context is how to simulate individual VAT burdens that arise from "spurious" VAT exemptions that cause, despite

\footnotetext{
${ }^{33}$ It is important to note that this means that all firms with VAT credit would face increased hotel cost as they pay the, now increased, net price without VAT. Thence, the hidden VAT burden increases, too, for firms will, in the end, shift this burden to their customers.
} 
VAT exemption, VAT burdens at the side of firms, and thus most likely are shifted to consumers as a "hidden" VAT burden, at least in the long run. Another issue is the correction for under-reporting of single consumption items, for the estimation error with respect to the budget, and, in this context, for the phase difference, that is, that the observed expenditures in the data generate revenue only with a certain delay. We provide a simulation procedure to cope with all these issues in a MSM. We argue that simulation of distributional and budget effects ought to be separated: correction of under-reporting is only applied for estimating budget effects, as it would bias the distributional analysis, given we have no information on group-specific under-reporting levels. The general model is considered as a blueprint for a VAT-MSM in any country with a VAT of the EU type. As an illustration of the functioning and the in-detail problems that arise in practice - and how to solve them - we applied the model to the specific case of Germany. Elaborating through this specific case, the strict data requirements for a VAT-MSM became clear, and must be considered at any attempt to replicate the model for another country. Finally, we have to keep in mind that our MSM involves some critical assumptions. All simulation results thus have to be discussed with this qualification. For instance, we assume that all VAT burdens faced by firms are shifted to the consumers in the long run. The research on VAT shifting, however, is not yet clear on that issue, although the current literature suggests that this is the case at the aggregate level.

There are two major directions for future research. First, the semi-behavioral model could be extended to a general equilibrium model where the household micro-data is combined with good supply data, calibrated with well-founded price-elasticity estimates of demand and supply for the single goods. Moreover, the MSM could be extended to incorporate a welfare analysis and labor market responses. 


\section{References}

Afentakis, A. and Bihler, W. (2005). Das Hochrechnungsverfahren beim unterjährigen Mikrozensus ab 2005, Wirtschaft und Statistik 10: 1039-1048.

Arulampalam, W., Devereux, M. P. and Maffini, G. (2012). The direct incidence of corporate income tax on wages, European Economic Review 56(6): 1038-1054.

Atkinson, A. B. and Stiglitz, J. E. (1976). The design of tax structure: Direct versus indirect taxation, Journal of Public Economics 6(1-2): 55-75.

Bach, S. (2005). Mehrwertsteuerbelastung der privaten Haushalte - Dokumentation des Mehrwertsteuer-Moduls des Konsumsteuer-Mikrosimulationsmodells des DIW Berlin auf Grundlage der Einkommens- und Verbrauchsstichprobe, DIW Berlin Data Documentation 10.

Ball, C. and Creedy, J. (2013). Population ageing and the growth of income and consumption tax revenue, New Zealand Treasury Working Paper 13/09, New Zealand Treasury.

Bauer, T., Kasten, T. and Siemers, L.-H. (2012). Business taxation and wages: Evidence from individual panel data, Discussion Paper 33-2012, MAGKS.

Beimann, B., Kambeck, R., Kasten, T. and Siemers, L.-H. (2011). Wer trägt den Staat? Eine Analyse von Steuer- und Abgabenlasten, RWI Positionen 43.

Besley, T. and Rosen, H. (1999). Sales taxes and prices: An empirical analysis, National Tax Journal 52(2): 157-178.

Boeters, S., Böhringer, C., Büttner, T. and Kraus, M. (2010). Economic effects of VAT reforms in Germany, Applied Economics 42(17): 2165-2182.

Bosch, L. H. M. and van den Noord, P. J. (1990). Alternative financing of social insurance systems, Journal of Policy Modeling 12(1): 61-76.

Boss, A. (1997). Untersuchungen zur Bemessungsgrundlage und zum kassenmäßigen Aufkommen der Steuern vom Umsatz, Kieler Arbeitspapier 844, Institut für Weltwirtschaft an der Universität Kiel.

Bye, B., Strøm, B. and Åvitsland, T. (2012). Welfare effects of VAT reforms: a general equilibrium analysis, International Tax and Public Finance 19(3): 368-392.

Carbonnier, C. (2007). Who pays sales taxes? Evidence from the French VAT Reforms, 1987-1999, Journal of Public Economics 91(5-6): 1219-1229.

Chen, D. L. (1999). World Consumption Economics, World Scientific Publishing, Singapore. (With Kenneth W. Clements).

Chesher, A. and Nesheim, L. (2006). Review of the literature on the statistical properties of linked datasets, DTI Occasional Paper 3, Department for Trade and Industry (DTI), U.K. 
Clements, K. W. (2008). Price elasticities of demand are minus one-half, Economics Letters 99(3): 490-493.

Clements, K. W. and Qiang, Y. (2003). The economics of global consumption patterns, Journal of Agricultural and Applied Economics 35(supplement): 21-37.

Cnossen, S. (1998). Global trends and issues in value added taxation, International Tax and Public Finance 5(3): 399-428.

Copenhagen Economics (2007). Study on reduced VAT applied to goods and services in the member states of the European Union, Research Report on behalf of the EU Commission, 6503 DG TAXUD.

Corlett, W. J. and Hague, D. C. (1953). Complementarity and the excess burden of taxation, Review of Economic Studies 21(1): 21-30.

Crawford, I., Keen, M. and Smith, S. (2010). Value added tax and excises, in J. Mirrlees, S. Adam, T. Besley, R. Blundell, S. Bond, R. Chote, M. Gammie, P. Johnson, G. Myles and J. Poterba (eds), Dimensions of Tax Design - The Mirrlees Review, Oxford University Press, pp. 275-422.

Decoster, A., Verwerft, D., Loughrey, J. and O'Donoghue, C. (2011). Microsimulation of indirect taxes, International Journal of Microsimulation 4(2): 41-56.

Destatis (2012a). Volkswirtschaftliche Gesamtrechnungen - Inlandsproduktsberechnung 2011, Detaillierte Jahresergebnisse, Fachserie 18(Reihe 1.4). Federal Statistical Office Germany.

Destatis (2012b). Volkswirtschaftliche Gesamtrechnungen - Input-Output-Rechnung 2008, Fachserie 18(Reihe 2). Federal Statistical Office Germany.

Destatis (2013). Finanzen und Steuern - Umsatzsteuerstatistik (Veranlagungen) 2008, Fachserie 14(Reihe 8.2). Federal Statistical Office Germany.

Deutsche Bundesbank (2008). Preis- und Mengenwirkungen der Mehrwertsteueranhebung zum 1. Januar 2007, Monatsbericht 60(4): 31-49.

Deville, J.-C. and Särndal, C.-E. (1992). Calibration estimators in survey sampling, Journal of the American Statistical Association 87(418): 376-382.

Diamond, P. A. and Mirrless, J. A. (1971). Optimal taxation and public production I and II: Production efficiency and tax rules, American Economic Review 61(1 and 3): 8-27, resp. 261-278.

DMB (2006). Alle Betriebskostenarten im Überblick, Presse aktuell (14. December). Deutscher Mieterbund.

Ericson, P. and Flood, L. (2012). A microsimulation approach to an optimal Swedish income tax, International Journal of Microsimulation 5(2): 2-21. 
European Commission (2006). Macroeconomic effects of a shift from direct to indirect taxation: A simulation for 15 EU member states, Technical report, European Commission services (DG TAXUD). Note presented by the European Commission services (DG TAXUD) at the $72^{\text {nd }}$ meeting of the OECD Working Party No. 2 on Tax Policy Analysis and Tax Statistics, Paris, 14-16 November 2006.

European Commission (2014). VAT Rates Applied in the Members States of the European Union, Brussels, European Commission - Taxation and Customs Union.

European Union (2006). VAT Directive 2006/112/EC, Official Journal of the European Union L 347. Decided 28 November 2006.

Eurostat (2013). Taxation Trends in the European Union, 2013 edn, European Union.

Fazio, G., Lam, K. H. and Ritchie, F. (2006). Sample bias in microeconometric analyses of official microdata, Report for the Department of Trade and Industry URN 06/737, Department of Trade and Industry (DTI).

Fritzsche, B., Kambeck, R. and von Löffelholz, H. (2003). Empirische Analyse der effektiven Inzidenz des deutschen Steuersystems, Untersuchungen des RheinischWestfälischen Instituts für Wirtschaftsforschung 42. Research report of RWI Essen on behalf of the Federal Ministry of Finance Germany.

Fuchs, V. R., Krueger, A. B. and Poterba, J. M. (1998). Economists' views about parameters, values, and policies: Survey results in labor and public economics, Journal of Economic Literature 36(3): 1387-1425.

German Council of Economic Experts (2005). Die Chance nutzen - Reformen mutig voranbringen, Annual Report 2005/06, German Council of Economic Experts.

German Council of Economic Experts (2007). Das Erreichte nicht verspielen, Annual Report 2007/08, German Council of Economic Experts.

German Council of Economic Experts (2010). Chancen für einen stabilen Aufschwung, Annual Report 2010/11, German Council of Economic Experts.

Gottfried, P. and Wiegard, W. (1991). Exemption versus zero rating: A hidden problem of VAT, Journal of Public Economics 46(3): 307-328.

Gupta, A. and Kapur, V. (2000). Microsimulation in Government Policy and Forecasting, Contributions to Economic Analysis, Amsterdam: North-Holland.

Harberger, A. C. (2002). Observations on tax reform in Columbia, Research report, University of California, Los Angeles.

Harberger, A. C. (2008). Corporation tax incidence: Reflections on what is known, unknown and unknowable, in J. W. Diamond and G. R. Zodrow (eds), Fundamental Tax Reform: Issues, Choices, and Implications, Cambridge: MIT Press, pp. 283-317.

Haufler, A. (2001). Taxation in a Global Economy, Cambridge University Press. 
Henderson, A. (1948). The case for indirect taxation, Economic Journal 58(232): 538-553.

Hicks, J. (1939). Value and Capital: An inquiry into some fundamental principles of economic theory, Clarendon press.

Immervoll, H., Lindström, K., Mustonen, E., Riihelä, M. and Viitamäki, H. (2005). Static data "ageing" techniques: Accounting for population changes in tax-benefit microsimulation models, EUROMOD Working Paper EM7/05, Institute for Social \& Economic Research, University of Essex.

Ismer, R., Kaul, A., Rath, S., Rei, W., Barbie, M., Riemer, K. and Wolf, M. (2010). Analyse und Bewertung der Strukturen von Regel- und ermäßigten Sätzen bei der Umsatzbesteuerung unter sozial-, wirtschafts-, steuer- und haushaltspolitischen Gesichtspunkten, Research Report, Berlin: Federal Ministry of Finance Germany.

Ito, H. (1954). Theorie und Technik der Nettoumsatzsteuer in Japan, FinanzArchiv/Public Finance Analysis, New Series 15(3): 447-478.

Jackman, R., Layard, R. and Nickell, S. J. (1996). Combatting unemployment: Is flexibility enough?, in OECD (ed.), Macroeconomic Policies and Structural Reform, Paris: OECD.

James, K. (2011). Exploring the origins and global rise of VAT, The VAT Reader (Tax Analysts) pp. 15-22. Available at SSRN: http://ssrn.com/abstract=2291281 or http://dx.doi.org/10.2139/ssrn.2291281.

Jenkins, G. and Lamech, R. (1991). Value added reform - proposals for the Dominican Republic, Technical report, Harvard Institute for International Development, Harvard University. Report for presentation at the Symposium Innovations in Tax System Reform: Proposals for the Dominican Republic.

Joseph, M. F. W. (1939). The excess burden of indirect taxation, Review of Economic Studies 6(3): 226-231.

Kaiser, H. and Spahn, P. B. (1989). On the efficiency and distributive justice of consumption taxes: A study on VAT in West Germany, Journal of Economics - Zeitschrift für Nationalökonomie 49(2): 199-218.

Keen, M. (2007). VAT attacks!, International Tax and Public Finance 14(4): 365-381.

Keen, M. and Smith, S. (1996). The future of value-added tax in the European Union, Economic Policy 11(23): 375-420.

Kotsogiannis, C. and Lopez-Garcia, M.-A. (2007). Imperfect competition, indirect tax harmonization and public goods, International Tax and Public Finance 14(2): 115133.

Lu, C. and Chen, C. (2008). China's VAT reform: Factors not to be ignored, China Legal Review 21. http://www.rwlawyers.com/upfile/2009123133605198.pdf (LexisNexis), retrieved 29 June, 2011. 
Luedeke, R. and Voelker, D. (2005). International aspects of income tax, German Tax and Business Law, Thomson - Sweet \& Maxwell, pp. 4,001-4,061.

Marshall, A. (1920). Principles of Economics, $8^{\text {th }}$ edn, London: Macmillan. First published in 1890.

Meghir, C. and Phillips, D. (2010). Labour supply and taxes, Dimensions of Tax Design: The Mirrlees Review, Institute for Fiscal Studies, Oxford University Press, pp. 202-274.

Merz, J. (2001). Was fehlt in der EVS? Eine Verteilungsanalyse hoher Einkommen mit der verknüpften Einkommensteuerstatistik für Selbständige und abhängig Beschäftigte, FFB Discussion-Paper 30. Available at SSRN: http://ssrn.com/abstract=1409932.

Merz, J., Stolze, H. and Imme, S. (2001). Adjust for windows - a program package to adjust microdata by the minimum information loss principle, FFB-Dokumentation 9, University of Lüneburg.

Mirrlees, J. (1971). Exploration in the theory of optimal income taxation, Review of Economic Studies 38(2): 205-229.

Musgrave, R. A. and Musgrave, P. B. (1984). Public Finance in Theory and Practice, $4^{\text {th }}$ edn, McGraw-Hill International Editions.

Neumark Report (1963). The EEC Reports on Tax Harmonization. The Report of the Fiscal and Financial Committee and the Reports of the Sub-groups A, B and C, International Bureau of Fiscal Documentation, Amsterdam.

Nie, H. and Yue, X. (2012). A study of the impact of indirect taxes on income distribution in rural and urban China, Journal of Chinese Tax 85 Policy 2(2): 30-44.

O’Donoghue, C., Baldini, M. and Mantovani, D. (2004). Modelling the redistributive impact of indirect taxes in Europe: an application of EUROMOD, EUROMOD Working Paper EMY/04, Institute for Social \& Economic Research (ISER), University of Essex.

Peffekoven, R. (2010). Reformbedarf bei der Mehrwertsteuer: Steuerausfälle, Wettbewerbsverzerrungen und Ineffizienzen vermeiden, Wirtschaftsdienst 90(9): 575-579.

Peichl, A. and Schaefer, T. (2009). FiFoSiM - an integrated tax benefit microsimulation and CGE model for Germany, International Journal of Microsimulation 2(1): 1-15.

Poterba, J. M. (1996). Retail price reactions to changes in state and local sales taxes, National Tax Journal 49(2): 165-176.

Premiere (2009). Geschäftsbericht 2008, http://ir.sky.de. Retrieved on May 22, 2014.

Ramsey, F. P. (1927). A contribution to the theory of taxation, Economic Journal 37(145): 47-61. 
RWI and FiFo (2007). Der Zusammenhang zwischen Steuerlast- und Einkommensverteilung, RWI Projektbericht, RWI Essen. Research report of RWI Essen in cooperation with FiFo Cologne on behalf of the Federal Ministry of Labour and Social Issues Germany.

RWI and FiFo (2009). Wer trägt den Staat? Die aktuelle Verteilung von Steuer- und Beitragslasten auf die Bevölkerung in Deutschland, RWI Projektbericht, RWI Essen. Research report of RWI Essen in cooperation with FiFo Cologne on behalf of the Federal Ministry of Economics and Technology Germany.

Scutella, R. (1997). Calculating the final incidence of Australian indirect taxes, Melbourne Institute Working Paper 18/97, Melbourne Institute of Applied Economic and Social Research.

Scutella, R. (1999). The final incidence of Australian indirect taxes, Australian Economic Review 32(4): 349-368.

Tinbergen Report (1953). Bericht über die durch die Umsatzsteuer aufgeworfenen Probleme auf dem gemeinsamen Markt, European Coal and Steel Community (ECSC).

UStG (2011[1967]). Umsatzsteuergesetz (UStG) - German Law of Sales Tax. Available at: http://www.gesetze-im-internet.de/bundesrecht/ustg_1980/gesamt.pdf. Retrieved June 28, 2011.

Wagenhals, G. (2004). Tax-benefit microsimulation models for Germany: A survey, IAWReport 32(1): 55-74. Institut für Angewandte Wirtschaftsforschung, Tübingen.

Wald, H. P. (1945). The classical indictment of indirect taxation, Quarterly Journal of Economics 59(4): 577-596.

Warren, N. (2008). Review of studies on the distributional impact of consumption taxes in OECD countries, OECD Social, Employment and Migration Working Papers 64, OECD Publishing. http://dx.doi.org/10.1787/241103736767.

Zwick, M. and Merz, J. (2007). MITAX - Mikroanalysen und Steuerpolitik, Vol. 7 of Statistik und Wissenschaft, Wiesbaden: Federal Office of Statistics Germany. 
Table 1: The Different VAT Rates of the EU Member States in 2014

\begin{tabular}{|c|c|c|c|c|}
\hline Country & Super-Reduced & Reduced & Standard & Parking \\
\hline Belgium & & $6 / 12$ & 21 & 12 \\
\hline Bulgaria & & 9 & 20 & \\
\hline Czech Republic & & 15 & 21 & \\
\hline Denmark & & & 25 & \\
\hline Germany & & 7 & 19 & \\
\hline Estonia & & 9 & 20 & \\
\hline Greece & & $6.5 / 13$ & 23 & \\
\hline Spain & 4 & 10 & 21 & \\
\hline France & 2.1 & $5.5 / 10$ & 20 & \\
\hline Croatia & 4 & 10 & 21 & \\
\hline Ireland & 4.8 & $9 / 13.5$ & 23 & 13.5 \\
\hline Italy & 4 & 10 & 22 & \\
\hline Cyprus & & $5 / 9$ & 19 & \\
\hline Latvia & & 12 & 21 & \\
\hline Lithuania & & $5 / 9$ & 21 & \\
\hline Luxembourg & 3 & $6 / 12$ & 15 & 12 \\
\hline Hungary & & $5 / 18$ & 27 & \\
\hline Malta & & $5 / 7$ & 18 & \\
\hline Netherlands & & 6 & 21 & \\
\hline Austria & & 10 & 20 & 12 \\
\hline Poland & & $5 / 8$ & 23 & \\
\hline Portugal & & $6 / 13$ & 23 & 13 \\
\hline Romania & & $5 / 9$ & 24 & \\
\hline Slovenia & & 9.5 & 22 & \\
\hline Slovakia & & 10 & 20 & \\
\hline Finland & & $10 / 14$ & 24 & \\
\hline Sweden & & $6 / 12$ & 25 & \\
\hline United Kingdom & & 5 & 20 & \\
\hline \multicolumn{5}{|c|}{$\begin{array}{l}\text { Source: European Commission }(2014) \text {, situation at } 13^{\text {th }} \text { January } 2014 \text {. - Rates in } \% \text {; } \\
\text { two numbers in column "reduced" separated by "/" represent two different reduced } \\
\text { VAT rates. }\end{array}$} \\
\hline
\end{tabular}


Table 2: Under-Reporting In IES2008 And CorRection FACtors

\begin{tabular}{|c|c|c|c|c|}
\hline expenditure [billion $€]^{\mathrm{a}}$ & IES2008 & $\begin{array}{l}\text { National } \\
\text { Account }\end{array}$ & Coverage & $\begin{array}{l}\text { Correction } \\
\text { Factor }^{\mathrm{a}}\end{array}$ \\
\hline \multirow{2}{*}{$\begin{array}{l}\text { priv. consumption of residentials } \\
\text { abroad }\end{array}$} & 1061.94 & 1317.31 & 0.81 & 1.24 \\
\hline & 21.07 & 62.05 & 0.34 & 2.95 \\
\hline \multicolumn{5}{|c|}{ goods taxed at reduced rate } \\
\hline food & 119.56 & 149.14 & 0.80 & 1.25 \\
\hline soft drinks & 13.59 & 17.44 & 0.78 & 1.28 \\
\hline medical utilities & 8.90 & 22.95 & 0.39 & 2.58 \\
\hline traffic, w/o air traffic & 12.08 & 19.33 & 0.63 & 1.60 \\
\hline cut flowers & 10.49 & 10.05 & 1.04 & 0.96 \\
\hline activities (culture, sports, leisure) & 13.86 & 32.96 & 0.42 & 2.38 \\
\hline books, magazines, newspapers & 13.76 & 19.08 & 0.72 & 1.39 \\
\hline accommodation (hotel etc.) & 12.15 & 12.99 & 0.94 & 1.07 \\
\hline \multicolumn{5}{|c|}{ goods that are exempted } \\
\hline actual rent payments & 106.65 & 92.73 & 1.15 & 0.87 \\
\hline assumed rents for owners & 128.53 & 127.20 & 1.01 & 0.99 \\
\hline medical services & 22.47 & 39.75 & 0.57 & 1.77 \\
\hline vehicles $^{\mathrm{b}}$ & 57.03 & 65.12 & 0.88 & 1.14 \\
\hline air traffic & 4.41 & 13.80 & 0.32 & 3.13 \\
\hline post/mail and courier services & 2.60 & 2.43 & 1.07 & 0.94 \\
\hline broadcasting fees & 7.87 & n.s. ${ }^{\mathrm{c}}$ & $\mathrm{n} / \mathrm{a}^{\mathrm{d}}$ & $1.02^{\mathrm{e}}$ \\
\hline lotto and gamble & 5.08 & 9.57 & 0.53 & 1.88 \\
\hline education & 9.64 & 12.66 & 0.76 & 1.31 \\
\hline
\end{tabular}

${ }^{a}$ Numbers are rounded, which may explain potential deviations.

${ }^{\mathrm{b}}$ Exempted are only the majority of used cars, but these are not specified in the national account data, so that the correction factor of vehicles in general is used.

${ }^{\mathrm{c}}$ n.s. - not specified. $\quad{ }^{\mathrm{d}} \mathrm{n} / \mathrm{a}$ - not applicable. $\quad{ }^{\mathrm{e}}$ The German collect-charges institution (GEZ) reported for 2008 a revenue of 7.26 billion $€$. In Germany there are, besides these fees for the public-law broadcasting, however, further charges for private TV channels. The turnover from subscriptions and pay-per-view of the market leader amounted to 0.77 billion $€$ (Premiere 2009: 33). Given there were no noteworthy competitors, the correction factor is estimated by $(7.26+0.77) / 7.87=1.02$.

Source: Income and Expenditure Survey 2008, Destatis (2012a), Premiere (2009), and own calculations. 
Table 3: Simulation Results for 2008

\begin{tabular}{|c|c|c|c|}
\hline category [billion $€$ ] & value & \multicolumn{2}{|c|}{ fraction $[\%]$} \\
\hline VAT revenue simulated & 174.48 & 100 & \\
\hline VAT open & 126.00 & 72.2 & 100 \\
\hline VAT due to $\tau^{s}$ & 110.99 & 63.6 & 88.1 \\
\hline VAT due to $\tau^{r}$ & 15.01 & 8.6 & 11.9 \\
\hline VAT hidden & 33.25 & 19.1 & 100 \\
\hline investment housing & 20.37 & 11.7 & 61.3 \\
\hline medical services & 7.07 & 4.1 & 21.3 \\
\hline social security system & 0.96 & 0.5 & 2.9 \\
\hline private insurances & 4.85 & 2.8 & 14.6 \\
\hline VAT non-residential & 3.77 & 2.2 & \\
\hline VAT territorial authorities & 11.46 & 6.6 & 100 \\
\hline on gross investment & 6.09 & 3.5 & 53.2 \\
\hline on inputs & 5.37 & 3.1 & 46.8 \\
\hline VAT officially reported & 175.99 & 100.9 & \\
\hline correction for phase difference & -0.77 & 0.4 & \\
\hline VAT officially reported, comparable & 175.22 & 100.4 & \\
\hline revenue correction factor $c f^{r e v}$ & 1.004 & & \\
\hline Fraction of total gross consumption taxed by & & 100 & \\
\hline standard rate $\tau^{s}$ & & 53 & \\
\hline reduced rate $\tau^{r}$ & & 17 & \\
\hline rate of zero & & 30 & \\
\hline Fraction of total net ${ }^{\mathrm{a}}$ consumption taxed by & & 100 & \\
\hline standard rate $\tau^{s}$ & & 49 & \\
\hline reduced rate $\tau^{r}$ & & 18 & \\
\hline rate of zero & & 33 & \\
\hline Relief $^{\mathrm{b}}$ in total (open) & 86.14 & 49.4 & 100 \\
\hline by reduced rate (open) & 25.73 & 14.7 & 29.9 \\
\hline by exemptions (open) & 60.41 & 34.6 & 70.1 \\
\hline
\end{tabular}

a 'Net' means 'before VAT', as a measure of real consumption.

b Relief compared to the benchmark where all goods would be taxed at standard rate $\tau^{s}$.

Source: Simulation with the extended RWI-VAT-SIM, mainly based on Income and Expenditure Survey 2008 (scientific use file of Siegen University, 80\% sample of survey), Destatis (2012a), Destatis (2012b), and own estimations. 
Table 4: Overall VAT Burden in 2008

\begin{tabular}{lccc}
\hline & \% of $\mathrm{HNI}^{\mathrm{a}}$ & \% of Net Consumption & \% of Gross Consumption \\
\hline Average burden & 9.2 & 13.2 & 11.9 \\
Mean ratio $^{\mathrm{b}}$ & $10.5^{* * *}$ & $13.7^{* * *}$ & $12.4^{* * *}$ \\
& {$[10.4,10.6]$} & {$[13.7,13.7]$} & {$[12.3,12.4]$} \\
Median ratio $^{\mathrm{b}}$ & $9.6^{* * *}$ & $13.8^{* * *}$ & $12.5^{* * *}$ \\
& {$[9.6,9.7]$} & {$[13.8,13.8]$} & {$[12.4,12.5]$} \\
\hline
\end{tabular}

${ }^{\mathrm{a}} \mathrm{HNI}$ - annual household net income; $\quad{ }^{\mathrm{b}}$ Significance levels: ${ }^{*} p<0.05,{ }^{* *} p<$ $0.01,{ }^{* * *} p<0.001 ; 95 \%$ confidence intervals in brackets, based on Huber-White corrected standard errors.

Source: Simulation with the extended RWI-VAT-SIM, mainly based on Income and Expenditure Survey 2008 (scientific use file of Siegen University, 80\% sample of survey), Destatis (2012a), Destatis (2012b), and own estimations. 
Table 5: Group-specific Household Income and VAT Burden in 2008

\begin{tabular}{|c|c|c|c|c|}
\hline & $\begin{array}{c}(1) \\
\text { HNI }^{\mathrm{a}} \\
\text { (median in } €)\end{array}$ & $\begin{array}{l}\quad(2) \\
\text { VAT payment } \\
\text { (median in } €)\end{array}$ & $\begin{array}{l}\text { (3) } \\
\text { Median Ratio } \\
\text { (in \%) }\end{array}$ & $\begin{array}{c}(4) \\
\text { Ratio }(1) /(2) \\
(\text { in } \%)\end{array}$ \\
\hline & \multicolumn{4}{|c|}{ Net Equivalence Income Decile (Sqrt-OECD)c } \\
\hline 1 & 9,092 & 1,072 & 11.2 & 11.8 \\
\hline 2 & 12,924 & 1,545 & 10.9 & 12.0 \\
\hline 3 & 18,772 & 1,950 & 10.7 & 10.4 \\
\hline 4 & 23,512 & 2,347 & 10.3 & 10.0 \\
\hline 5 & 27,576 & 2,699 & 10.0 & 9.8 \\
\hline 6 & 31,752 & 3,010 & 9.5 & 9.5 \\
\hline 7 & 36,936 & 3,370 & 9.1 & 9.1 \\
\hline 8 & 43,880 & 3,828 & 8.6 & 8.7 \\
\hline 9 & 54,932 & 4,373 & 7.8 & 8.0 \\
\hline \multirow[t]{2}{*}{10} & 79,452 & 5,265 & 6.5 & 6.6 \\
\hline & \multicolumn{4}{|c|}{ Net Equivalence Income Bracket (Sqrt-OECD) ${ }^{\mathrm{c}}$} \\
\hline below 10,000 EUR & 8,968 & 1,063 & 11.3 & 11.8 \\
\hline 10,000 to 20,000 & 18,592 & 2,019 & 10.6 & 10.9 \\
\hline 20,000 to 30,000 & 34,068 & 3,198 & 9.3 & 9.4 \\
\hline 30,000 to 40,000 & 50,568 & 4,165 & 8.1 & 8.2 \\
\hline 40,000 to 50,000 & 64,412 & 4,830 & 7.3 & 7.5 \\
\hline 50,000 to 60,000 & 77,328 & 5,254 & 6.6 & 6.8 \\
\hline 60,000 to 70,000 & 91,544 & 5,729 & 6.3 & 6.3 \\
\hline 70,000 to 80,000 & 105,500 & 5,825 & 5.3 & 5.5 \\
\hline 80,000 to 90,000 & 118,240 & 6,121 & 5.1 & 5.2 \\
\hline 90,000 to 100,000 & 133,388 & 6,584 & 4.6 & 4.9 \\
\hline 100,000 to 110,000 & 148,700 & 7,436 & 5.0 & 5.0 \\
\hline 110,000 to 120,000 & 158,012 & 5,643 & 4.3 & 3.6 \\
\hline \multirow[t]{2}{*}{120,000 EUR or more } & 177,244 & 4,761 & 3.1 & 2.7 \\
\hline & \multicolumn{4}{|c|}{ Household Type } \\
\hline single & 17,400 & 1,756 & 10.2 & 10.1 \\
\hline single parent: 1 child & 21,140 & 2,211 & 10.3 & 10.5 \\
\hline single parent: 2 or more children & 26,948 & 2,733 & 10.2 & 10.1 \\
\hline Pair: no child & 34,676 & 3,293 & 9.4 & 9.5 \\
\hline Pair: 1 child & 44,616 & 3,971 & 9.0 & 8.9 \\
\hline Pair: 2 children & 50,360 & 4,428 & 8.8 & 8.8 \\
\hline Pair: 3 or more children & 53,912 & 4,681 & 8.8 & 8.7 \\
\hline other & 43,600 & 3,795 & 8.9 & 8.7 \\
\hline \multicolumn{5}{|c|}{ Social Class } \\
\hline self-employed farmer & 40,352 & 4,004 & 10.6 & 9.9 \\
\hline self-empl. business-/craftsman, freelance & 41,208 & 3,634 & 8.9 & 8.8 \\
\hline public servant & 49,832 & 3,867 & 8.1 & 7.8 \\
\hline white-collar worker & 34,964 & 3,196 & 9.2 & 9.1 \\
\hline blue-collar worker & 35,332 & 3,248 & 9.4 & 9.2 \\
\hline unemployed & 11,860 & 1,278 & 10.6 & 10.8 \\
\hline retired employee & 22,164 & 2,262 & 10.2 & 10.2 \\
\hline retired public servant & 47,952 & 3,802 & 8.1 & 7.9 \\
\hline other non-working & 12,084 & 1,369 & 10.8 & 11.3 \\
\hline & \multicolumn{4}{|c|}{ Gender of Main Income Earner } \\
\hline male & 35,764 & 3,289 & 9.3 & 9.2 \\
\hline female & 20,548 & 2,102 & 10.1 & 10.2 \\
\hline Total & 28,516 & 2,748 & 9.6 & 9.6 \\
\hline
\end{tabular}

${ }^{\mathrm{a}} \mathrm{HNI}$ - annual household net income; $\quad{ }^{\mathrm{b}}$ Annual VAT payment; $\quad{ }^{\mathrm{c}}$ Deciles and income brackets are calculated based on net equivalence income, which, following the OECD's square-root approach, is determined by (annual) household net income divided by the square root of the number of members of household.

Source: Simulation with the extended RWI-VAT-SIM, mainly based on Income and Expenditure Survey 2008 (scientific use file of Siegen University, 80\% sample of survey), Destatis (2012a), Destatis (2012b), and own estimations. 
Table 6: MeAN VAT BURDen IN 2008

Mean VAT-burden

on $\mathrm{HNI}^{\mathrm{a}}$ on Gross Consumpt. on Net Consumpt. in $€$ p.a.

$\begin{array}{lll}\text { (in \%) (in \%) } & \text { (in \%) }\end{array}$

\begin{tabular}{|c|c|c|c|c|}
\hline & \multicolumn{4}{|c|}{ Net Equivalence Income Decile (Sqrt-OECD) ${ }^{\mathrm{b}}$} \\
\hline 1 & 15.0 & 11.2 & 12.3 & $€ 1,267$ \\
\hline 2 & 11.6 & 11.7 & 12.9 & $€ 1,730$ \\
\hline 3 & 11.4 & 12.2 & 13.5 & $€ 2,160$ \\
\hline 4 & 11.1 & 12.4 & 13.7 & $€ 2,591$ \\
\hline 5 & 10.7 & 12.6 & 14.0 & $€ 2,963$ \\
\hline 6 & 10.3 & 12.6 & 14.0 & $€ 3,298$ \\
\hline 7 & 9.8 & 12.7 & 14.1 & $€ 3,679$ \\
\hline 8 & 9.2 & 12.7 & 14.2 & $€ 4,104$ \\
\hline 9 & 8.6 & 12.8 & 14.2 & $€ 4,779$ \\
\hline 10 & 7.1 & 12.7 & 14.1 & $€ 5,858$ \\
\hline \multicolumn{5}{|c|}{ Household Type } \\
\hline single & 11.1 & 12.2 & 13.4 & $€ 2,034$ \\
\hline single parent: 1 child & 10.9 & 12.1 & 13.3 & $€ 2,511$ \\
\hline single parent: 2 or more children & 10.5 & 11.8 & 13.0 & $€ 3,042$ \\
\hline Pair: no child & 10.3 & 12.5 & 13.9 & $€ 3,759$ \\
\hline Pair: 1 child & 10.0 & 12.7 & 14.1 & $€ 4,413$ \\
\hline Pair: 2 children & 9.4 & 12.5 & 13.9 & $€ 4,843$ \\
\hline Pair: 3 or more children & 9.3 & 12.2 & 13.5 & $€ 5,175$ \\
\hline other & 9.6 & 12.5 & 13.8 & $€ 4,316$ \\
\hline \multicolumn{5}{|c|}{ Social Class } \\
\hline self-employed farmer & 14.2 & 12.8 & 14.2 & $€ 4,531$ \\
\hline self-empl. business-/craftsman, freelance & 10.2 & 12.7 & 14.1 & $€ 4,278$ \\
\hline public servant & 8.9 & 12.2 & 13.6 & $€ 4,353$ \\
\hline white-collar worker & 9.8 & 12.9 & 14.3 & $€ 3,714$ \\
\hline blue-collar worker & 10.2 & 12.7 & 14.1 & $€ 3,517$ \\
\hline unemployed & 11.3 & 11.2 & 12.2 & $€ 1,513$ \\
\hline retired employee & 11.1 & 12.0 & 13.3 & $€ 2,625$ \\
\hline retired public servant & 9.2 & 11.6 & 12.9 & $€ 4,274$ \\
\hline other non-working & 15.4 & 11.3 & 12.5 & $€ 1,715$ \\
\hline \multicolumn{5}{|c|}{ Gender of Main Income Earner } \\
\hline male & 10.2 & 12.5 & 13.8 & $€ 3,710$ \\
\hline female & 11.0 & 12.2 & 13.5 & $€ 2,543$ \\
\hline Total & 10.5 & 12.4 & 13.7 & $€ 3,243$ \\
\hline \multicolumn{5}{|c|}{$\begin{array}{l}\text { a HNI - annual household net income; }{ }^{\mathrm{b}} \text { Deciles are calculated based on net equivalence income, which, } \\
\text { following the OECD's square-root approach, is determined by (annual) household net income divided by the } \\
\text { square root of the number of members of household. }\end{array}$} \\
\hline \multicolumn{5}{|c|}{$\begin{array}{l}\text { Source: Simulation with the extended RWI-VAT-SIM, mainly based on Income and Expenditure Survey } 2008 \\
\text { (scientific use file of Siegen University, } 80 \% \text { sample of survey), Destatis (2012a), Destatis (2012b), and own } \\
\text { estimations. }\end{array}$} \\
\hline
\end{tabular}


Table 7: Group-specific Propensity and Structure of Consumption in 2008

Mean (in \%)

Consumpt. Prop. ${ }^{\mathrm{a}}$ Standard rate $^{\mathrm{b}}$ Reduced rate $^{\mathrm{b}}$ Exemptions $^{\mathrm{b}}$

single

single parent: 1 child

single parent: 2 o. m. children

Pair: no child

Pair: 1 child

Pair: 2 children

Pair: 3 or more children

other

Net Equivalence Income Decile (Sqrt-OECD) ${ }^{\mathrm{c}}$

$\begin{array}{rrrr}130.3 & 40.8 & 20.7 & 38.4 \\ 99.1 & 44.1 & 20.8 & 35.2 \\ 94.0 & 47.3 & 19.9 & 32.7 \\ 89.8 & 48.5 & 19.1 & 32.3 \\ 85.4 & 50.2 & 18.6 & 31.1 \\ 81.9 & 50.8 & 18.0 & 31.3 \\ 77.9 & 51.2 & 17.6 & 31.2 \\ 73.2 & 51.6 & 17.0 & 31.4 \\ 67.8 & 52.2 & 16.1 & 31.6 \\ 56.8 & 52.7 & 15.0 & 32.3\end{array}$

\section{Household Type}

$\begin{array}{rccc}92.0 & 46.9 & 17.4 & 35.7 \\ 91.4 & 47.5 & 19.2 & 33.3 \\ 90.2 & 46.8 & 20.7 & 32.5 \\ 83.2 & 50.5 & 18.7 & 30.8 \\ 79.5 & 51.7 & 18.5 & 29.8 \\ 75.1 & 50.8 & 18.9 & 30.2 \\ 76.3 & 49.1 & 20.2 & 30.7 \\ 78.4 & 49.5 & 18.6 & 31.9 \\ & & & \\ 111.7 & \text { Social Class } & & 31.8 \\ 80.8 & 50.4 & 17.9 & 32.9 \\ 73.5 & 50.3 & 16.8 & 33.2 \\ 76.9 & 50.8 & 16.0 & 31.1 \\ 81.3 & 51.7 & 17.2 & 30.6 \\ 100.6 & 50.7 & 18.6 & 37.2 \\ 92.4 & 42.2 & 20.7 & 33.8 \\ 78.6 & 46.6 & 19.6 & 37.0 \\ 132.0 & 47.4 & 16.4 & \end{array}$

self-employed farmer

self-empl. business-/craftsman, freelance

Gender of Main Income Earner
49.9

public servant

blue-collar worker

unemployed

retired employee

retired public servant

other non-working

\begin{tabular}{llllr} 
male & 82.3 & 49.9 & 18.2 & 31.9 \\
female & 90.6 & 47.6 & 18.4 & 34.0 \\
\hline Total & 85.6 & 49.0 & 18.3 & 32.8 \\
\hline
\end{tabular}

a The documented propensity to consume is consumption viable to VAT divided by household net income (in $\%$ ); $\quad$ bet consumption burdened by $\tau^{x}, x=\{s, r, 0\}$, as a fraction of total net consumption viable to VAT openly; $\quad{ }^{\mathrm{c}}$ Deciles are calculated based on net equivalence income, which, following the OECD's square-root approach, is determined by (annual) household net income divided by the square root of the number of members of household.

Source: Simulation with the extended RWI-VAT-SIM, mainly based on Income and Expenditure Survey 2008 (scientific use file of Siegen University, 80\% sample of survey), Destatis (2012a), Destatis (2012b), and own estimations. 
Table 8: FinANCING OF VAT BUdget in 2008

\begin{tabular}{|c|c|c|c|c|c|c|c|}
\hline & \multicolumn{4}{|c|}{ Population Fraction } & \multicolumn{3}{|c|}{ Sourcing Fraction } \\
\hline & $\begin{array}{r}\text { Freq. } \\
\text { (in million) }\end{array}$ & $\begin{array}{r}\text { Fraction } \\
\quad \text { (in \%) }\end{array}$ & $\begin{array}{r}\text { Sum } \\
\text { (in \%) }\end{array}$ & $\begin{array}{l}\text { inv. Sum } \\
\quad \text { (in \%) }\end{array}$ & $\begin{array}{l}\text { Fraction }^{\mathrm{a}} \\
\quad \text { (in \%) }\end{array}$ & $\begin{array}{l}\text { acc. Fract. } \\
\text { (in \%) }\end{array}$ & $\begin{array}{l}\text { inv. Fract. } \\
\text { (in \%) }\end{array}$ \\
\hline & \multicolumn{7}{|c|}{ Net Equivalence Income Decile (Sqrt-OECD) $)^{\mathrm{b}}$} \\
\hline 1 & 4,404 & 10.0 & 10.0 & 100.0 & 3.9 & 3.9 & 100.0 \\
\hline 2 & 4,403 & 10.0 & 20.0 & 90.0 & 5.3 & 9.2 & 96.1 \\
\hline 3 & 4,404 & 10.0 & 30.0 & 80.0 & 6.7 & 15.9 & 90.8 \\
\hline 4 & 4,403 & 10.0 & 40.0 & 70.0 & 8.0 & 23.9 & 84.1 \\
\hline 5 & 4,404 & 10.0 & 50.0 & 60.0 & 9.1 & 33.0 & 76.1 \\
\hline 6 & 4,405 & 10.0 & 60.0 & 50.0 & 10.2 & 43.2 & 67.0 \\
\hline 7 & 4,402 & 10.0 & 70.0 & 40.0 & 11.3 & 54.5 & 56.8 \\
\hline 8 & 4,403 & 10.0 & 80.0 & 30.0 & 12.7 & 67.2 & 45.5 \\
\hline 9 & 4,403 & 10.0 & 90.0 & 20.0 & 14.7 & 81.9 & 32.8 \\
\hline \multirow[t]{2}{*}{10} & 4,403 & 10.0 & 100.0 & 10.0 & 18.1 & 100.0 & 18.1 \\
\hline & \multicolumn{7}{|c|}{ Net Equivalence Income Bracket (Sqrt-OECD)b } \\
\hline below 10,000 EUR & 4,193 & 9.5 & 9.5 & 100.0 & 3.7 & 3.7 & 100.0 \\
\hline 10,000 to 20,000 & 15,669 & 35.6 & 45.1 & 90.5 & 24.7 & 28.4 & 96.3 \\
\hline 20,000 to 30,000 & 12,944 & 29.4 & 74.5 & 54.9 & 31.7 & 60.1 & 71.6 \\
\hline 30,000 to 40,000 & 5,847 & 13.3 & 87.8 & 25.5 & 18.5 & 78.5 & 39.9 \\
\hline 40,000 to 50,000 & 2,727 & 6.2 & 94.0 & 12.2 & 10.0 & 88.5 & 21.5 \\
\hline 50,000 to 60,000 & 1,242 & 2.8 & 96.8 & 6.0 & 5.0 & 93.5 & 11.5 \\
\hline 60,000 to 70,000 & 605 & 1.4 & 98.2 & 3.2 & 2.7 & 96.2 & 6.5 \\
\hline 70,000 to 80,000 & 321 & 0.7 & 98.9 & 1.8 & 1.4 & 97.6 & 3.8 \\
\hline 80,000 to 90,000 & 174 & 0.4 & 99.3 & 1.1 & 0.9 & 98.5 & 2.4 \\
\hline 90,000 to 100,000 & 115 & 0.3 & 99.6 & 0.7 & 0.6 & 99.0 & 1.5 \\
\hline 100,000 to 110,000 & 64 & 0.2 & 99.7 & 0.5 & 0.4 & 99.4 & 1.0 \\
\hline 110,000 to 120,000 & 53 & 0.1 & 99.8 & 0.3 & 0.3 & 99.7 & 0.6 \\
\hline \multirow[t]{2}{*}{120,000 EUR or more } & 80 & 0.2 & 100.0 & 0.2 & 0.3 & 100.0 & 0.3 \\
\hline & \multicolumn{7}{|c|}{ Household Type } \\
\hline single & 17,367 & 39.4 & 39.4 & 100.0 & 24.7 & 24.7 & 100.0 \\
\hline single parent: 1 child & 1,854 & 4.2 & 43.7 & 60.6 & 3.3 & 28.0 & 75.3 \\
\hline single parent: 2 or more ch. & 679 & 1.5 & 45.2 & 56.3 & 1.4 & 29.4 & 72.0 \\
\hline Pair: no child & 12,798 & 29.1 & 74.3 & 54.8 & 33.7 & 63.1 & 70.6 \\
\hline Pair: 1 child & 4,428 & 10.1 & 84.3 & 25.7 & 13.7 & 76.8 & 36.9 \\
\hline Pair: 2 children & 3,995 & 9.1 & 93.4 & 15.7 & 13.6 & 90.4 & 23.2 \\
\hline Pair: 3 or more children & 1,364 & 3.1 & 96.5 & 6.6 & 4.9 & 95.3 & 9.6 \\
\hline \multirow[t]{2}{*}{ other } & 1,548 & 3.5 & 100.0 & 3.5 & 4.7 & 100.0 & 4.7 \\
\hline & \multicolumn{7}{|c|}{ Social Class } \\
\hline self-employed farmer & 222 & 0.5 & 0.5 & 100.0 & 0.7 & 0.7 & 100.0 \\
\hline other self-employed & 2,506 & 5.7 & 6.2 & 99.5 & 7.5 & 8.2 & 99.3 \\
\hline public servant & 1,710 & 3.9 & 10.1 & 93.8 & 5.2 & 13.4 & 91.8 \\
\hline white-collar worker & 14,472 & 32.9 & 42.9 & 89.9 & 37.6 & 51.1 & 86.6 \\
\hline blue-collar worker & 7,055 & 16.0 & 59.0 & 57.1 & 17.4 & 68.4 & 48.9 \\
\hline unemployed & 3,388 & 7.7 & 66.7 & 41.0 & 3.6 & 72.0 & 31.6 \\
\hline retired employee & 11,640 & 26.4 & 93.1 & 33.3 & 21.4 & 93.4 & 28.0 \\
\hline retired public servant & 1,623 & 3.7 & 96.8 & 6.9 & 4.9 & 98.3 & 6.6 \\
\hline \multirow[t]{2}{*}{ other non-working } & 1,417 & 3.2 & 100.0 & 3.2 & 1.7 & 100.0 & 1.7 \\
\hline & \multicolumn{7}{|c|}{ Gender of Main Income Earner } \\
\hline male & 26,401 & 60.0 & 60.0 & 100.0 & 68.6 & 68.6 & 100.0 \\
\hline female & 17,632 & 40.0 & 100.0 & 40.0 & 31.4 & 100.0 & 31.4 \\
\hline
\end{tabular}


Table 9: Results to Hotel-Accommodation Simulation for 2008

\begin{tabular}{|c|c|c|c|c|c|c|c|}
\hline & $\begin{array}{c}(1) \\
\text { Status Quo }\end{array}$ & $\begin{array}{c}(2) \\
\text { Static }\end{array}$ & $\begin{array}{c}(3) \\
\text { Semi-Beh. } 1\end{array}$ & $\begin{array}{c}(4) \\
\text { Semi-Beh. } 2\end{array}$ & $\begin{array}{c}(5) \\
\text { Semi-Beh. } 3\end{array}$ & $\begin{array}{c}(6) \\
\text { Semi-Beh. } 4\end{array}$ & unit \\
\hline Expenditures & 12.99 & 11.67 & 11.87 & 12.11 & 12.23 & 12.39 & billion $€$ \\
\hline VAT rate & 19 & 7 & 7 & 7 & 7 & 7 & $\%$ \\
\hline Elasticity $^{\mathrm{a}}$ & $\mathrm{n} / \mathrm{a}^{\mathrm{b}}$ & 0 & $\begin{array}{l}-0.13 \text { (poor) } \\
-0.15 \text { (rich) }\end{array}$ & $\begin{array}{l}-0.37 \text { (poor) } \\
-0.32 \text { (rich) }\end{array}$ & -0.426 & -0.547 & $\mathrm{n} / \mathrm{a}^{\mathrm{b}}$ \\
\hline VAT revenue & 2.08 & 0.77 & 0.96 & 1.20 & 1.33 & 1.49 & billion $€$ \\
\hline $\begin{array}{l}\text { Budget Effect } \\
\text { due to response }\end{array}$ & $\mathrm{n} / \mathrm{a}^{\mathrm{b}}$ & $\begin{array}{c}-1.32 \\
0.00\end{array}$ & $\begin{array}{c}-1.12 \\
0.19\end{array}$ & $\begin{array}{c}-0.88 \\
0.43\end{array}$ & $\begin{array}{c}-0.76 \\
0.56\end{array}$ & $\begin{array}{c}-0.60 \\
0.72\end{array}$ & $\begin{array}{l}\text { billion } € \\
\text { billion } €\end{array}$ \\
\hline
\end{tabular}

${ }^{\mathrm{a}}$ In columns (3) and (4) elasticities are drawn from Clements and Qiang (2003), who provide estimates for poor and rich countries, that we used for the first to fifth decile (poor) and the sixth to tenth decile (rich); in column (5) and (6) elasticities are drawn from Chen (1999); ${ }^{b} \mathrm{n} / \mathrm{a}-$ not applicable.

Source: Simulation with the extended RWI-VAT-SIM, mainly based on Income and Expenditure Survey 2008 (scientific use file of Siegen University, $80 \%$ sample of survey), Destatis (2012a), Destatis (2012b), and own estimations. 


\section{Appendix}

\section{A The Income and Expenditure Survey (IES)}

The IES provides detailed information on gross and net income, age, job, sex, marital status, children, and, most important, on final consumption expenditures. The IES covers more than 200 items of expenditures. The micro unit in the IES is basically the household, that is, the group of persons that live in one housing unit. The manifold detailed expenditure information allow a comprehensive in-depth analysis of consumption taxes by different socio-economic and socio-demographic groups. The IES is cross-section data and conducted at five-year intervals. Participation of survey is on a voluntary basis. In every survey year, about 60,000 households are contacted, which represents the "largest survey of its kind throughout the European Union." 34 The IES is based on quota sampling, that is, households are selected and included following a specified quota plan, in order to reach representativity. In a first step, the households are divided by Länder (the 16 German states), and then by household type, social status of the main income earner, and finally by net household income. Participating households record their expenditures in a household book for three month. "To ensure an even distribution across the year, the overall sample" is constructed on basis of four equal sized household groups, each covering one of the four quarters of the year. The 2008 wave of the IES is available since autumn 2010. The statistical office undertakes several plausibility checks during the processing stage. Therefore, given the large number of observations the data "are highly accurate and reliable." Due to the quota plan and comparison with the German micro census data, the data are "representative for almost all households ... However, the [IES] does not provide data on persons living in communal establishments and institutions because they are not included in the household definition applied in the survey. The [IES] neither provides data on households with a monthly net income of $€ 18,000$ or more as the number of these households participating in the survey is usually not sufficient to provide reliable information on their standards of living." This upper income threshold causes that there is a selection bias toward the poorer income brackets, and an under-representation of the very-high-income households. ${ }^{35}$ The next IES survey took place in the year 2013, and will be available not before autumn of the year 2015. The IES provides for each household a weight to produce representative results, that we use in all our simulations. The weights

\footnotetext{
${ }^{34}$ Any statements in quotes within this description are taken from the text titled "Sample survey of income and expenditure (EVS)", to be found at www.destatis.de.

${ }^{35}$ For a detailed scrutiny of the issue, cf. Merz (2001).
} 
are calculated based on a detailed generalized regression estimation (cf., e.g., Afentakis and Bihler 2005). The assumption of an i.i.d. random sample, however, is still not fully fulfilled because the survey follows an approach of quota sampling. ${ }^{36}$

\footnotetext{
${ }^{36}$ Therefore, we applied a bootstrapping technique in one of our research projects (RWI and FiFo 2007), in order to demonstrate the related uncertainty about the results by a confidence interval around the mean or median results. It turned out that bootstrapping nicely qualify results that rely on a comparatively low number of group specific observations by big confidence intervals.
} 